\title{
A COURSE INDICATOR OF POINTER TYPE FOR THE VISUAL RADIO RANGE-BEACON SYSTEM
}

\author{
By F. W. Dunmore
}

ABSTRACT

A form of tuned-reed radio range-beacon course indicator is described, called a reed converter, in which the course indications are not given by observing the two reed motions as heretofore, but by means of a zero-center pointer type indicating instrument. The motion of the two reeds generates small alternating voltages, which when rectified by oxide rectifiers and passed in opposing polarities through a zero-center indicating instrument, serve to give course indications by the deflection of the indicating instrument needle in the direction of deviation of the airplane from the course.

The reed converter consists of two reed units, two oxide rectifiers, and the course-indicating instrument. The driving coils of the two units are connected in series to the output of the aircraft radio receiving set.

Each reed converter unit consists of a polarized reed tuned to one of the beacon modulation frequencies. The reed vibrates between a set of driving coils which are supplied with the signal from the radio range. The same reed extends between a set of pick-up coils, the motion of the reed generating a voltage in these coils.

Since a null method of course indication is used, it is necessary to provide a signal-volume indicator in the form of a 0-500 microammeter in the output circuit of the oxide rectifiers. It is connected so that the output from each rectifier deflects the instrument pointer in the same direction. It not only serves to enable a pilot to tune in the beacon signal and to control the volume, but also indicates a cessation of this signal or a failure of any part of the radio receiving set or reed converter units.

Several forms of converter selector-switch circuit arrangements are shown whereby it is possible to use the reed converter course indicator on any course of a 4 or 12 course radio range beacon. By setting a pointer to the color of the range beacon to be flown and the direction of flight on it, the proper two-reed units are selected by this switch, and their outputs connected in the correct polarity to the course-indicating instrument so that its pointer will deflect in the same direction as the deviation of the airplane from the course.

As the course-sharpness indications depend upon the signal level delivered to the indicating instrument, this sharpness may be controlled at will.

The combination of this course indicator and the high-frequency fog landing beam course indicator into one indicating instrument is described. This instrument, when provided with a suitable switch, may be made to give two more indications; main radio range-beacon course and signal volume indication.

The advantages and disadvantages of the reed converter as compared to the tuned-reed indicator are discussed.

\section{CONTENTS}

I. Introduction

II. The tuned-reed converter unit....

1. Principles of operation.

2. Details of design

(a) The reed-converter unit design

(b) The reed-converter unit mounting

(c) Sensitivity .............

(d) Sharpness of resonance 
III. The course-selector switch, deviometer, volume indicator, and

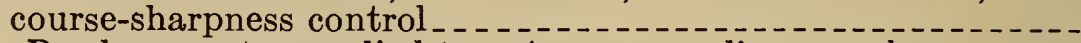

1. Reed converter applied to a 4 -course radio range beacon---

2. Use of the deviometer, volume indicator, and course-sharpness control

(a) The deviometer

(b) The volume indicator

(c) The course-sharpness control

3. Reed converter applied to 4- or 12-course beacon.......

(a) Two-unit plug-in arrangement.......

(b) Three-unit dual-control arrangement

(c) Three-unit single-control arrangement..........

IV. Applications of the reed-converter course indicator.

Page

1. As a main airways beacon course indicator

165

2. Use in holding an airplane automatically on a radio-beacon course a course indicator on the runway localizing beacon for

3. Use as a course indicator on the runway localizing beacon for
blind-landing purposes

4. Combination with turn indicator

V. Comparison of reed converter with reed indicator

1. Advantages of reed converter 169

VI. Conclusion. Disadvantages of reed converter

169

169

\section{INTRODUCTION}

The tuned-reed type of visual indicator ${ }^{1}$ is used to give a pilot a visual indication as to whether or not he is flying on a specified doublemodulation radio range-beacon course and, if not, to which side and how much he has deviated. This type of tuned-reed indicator gives the course indication continuously by means of two vibrating reeds, the relative amplitudes of which indicate the position of the airplane with respect to the beacon course. In order to observe the reed vibration, each reed carries a white tab on its free end. These two tabs produce two adjacent white lines when the reeds vibrate. It is the relative length of these two lines which the pilot observes. Each reed is tuned to one of the frequencies of modulation used at the radio range beacon. The course is a zone in space where the strengths of the beacon-modulation frequencies are equal, each zone being indicated to the pilot by amplitude equality of the two vibrating reeds. A deviation from the course is indicated by an increase in that reed amplitude on the side to which the airplane has deviated and an equivalent decrease in the other reed amplitude.

The development of a form of reed indicator is described in this paper in which the course indications are not given by observing the reed motions, but by means of a zero-center pointer-type instrument. The motions of the two reeds generate small alternating voltages, which, when rectified and passed in opposing polarities through the zero-center indicating instrument, serve to give course indications by the deflection of the indicating instrument needle in the direction of the airplane's deviation from the course. A form of course-selector switch is also described which makes possible the use of this type of visual course indicator on any one of the courses of a 4 or 12 course radio range beacon in such manner that the instrument needle deflects in the same direction as the deviation of the airplane from the course,

1 J. H. Dellinger, H. Diamond, and F. W. Dunmore, Development of the Visual Type Airway Radio Beacon System, B. S. Jour. Research, 4 (R Pi59), p. 425; March, 1930; Proc. I. R. E., 18, p. 796; May, 1930.

F. W. Dunmore, A Tuned Reed Course Indicator for the 4 and 12 Course Aircraft Radio Range. B. S. Jour. Research, 1 (RP160), p. 461; April 1930; Proc. I. R. E., 18, p. 963; June, 1830. 
regardless of which course is being flown or the direction of flight. It is only necessary for the pilot to set the pointer of the switch to the color of the beacon course he is to fly, and to the direction of flight along this course; that is, to "To" or "From" the readiobeacon. This switch selects the two proper reed-converter units, and connects their outputs in the proper polarity to the zero-center indicating instrument, thus causing the needle to deflect in the direction of deviation of the airplane from the course. In its complete form the reed converter consists of three units, one tuned to 65 cycles, another to 86.67 , and the third to 108.33 cycles. In this form it is applicable for use on the 12-course visual type radio range beacon or on 4-course beacons having different combinations of the above frequencies.

\section{THE TUNED-REED CONVERTER UNIT}

\section{PRINCIPLES OF OPERATION}

The tuned-reed converter in its simplest form is shown in Figure 1. It consists of a polarized metal reed vibrating between two sets of

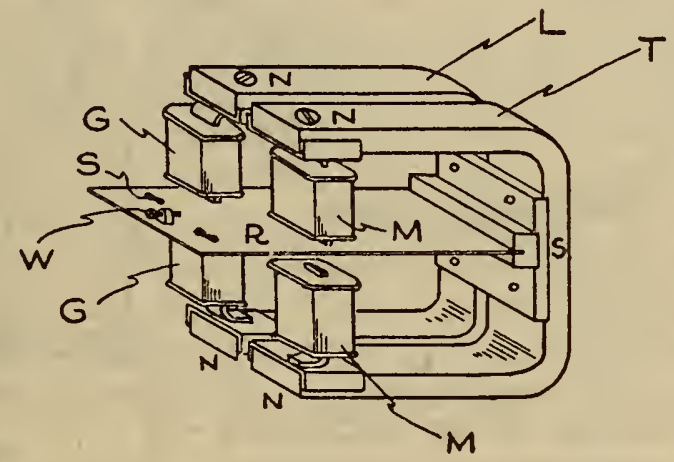

$\underline{C}$

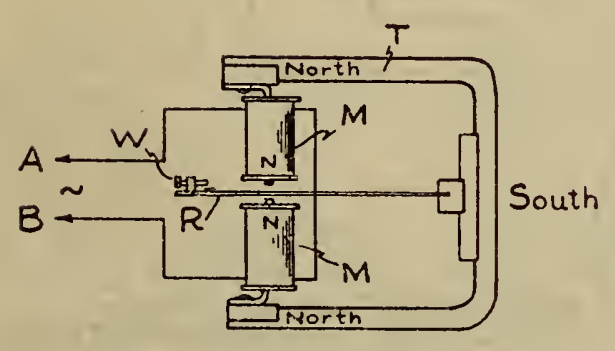

$\underline{A}$

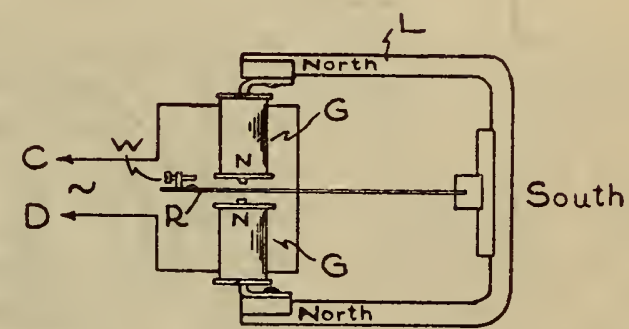

$\underline{B}$

Figure 1.-Tuned-reed converter illustrating method of operation

electromagnet coils, one set being supplied with an alternating current of the frequency to which the reed is tuned, thus causing it to vibrate, and the other set, by virtue of the changing magnetic flux caused by the vibrating reed, generates an alternating voltage of the same frequency. At $A$ (fig. 1 ) is shown a simple reed driving unit, the magnet $T$ polarizing the reed $R$ with a south pole, and the pole pieces of the electromagnets $M$ with a north pole. With the electromagnet coils connected in series in the proper electrical polarity; that is, so that current flowing through them in series will tend to produce opposite magnetic polarities at the pole tips, the reed will, during one-half 
cycle of the driving current, be attracted by the upper electromagnet and repelled by the lower one, thus moving up. During the second half cycle of the driving current the net driving force reverses. Thus when an alternating current of the natural frequency of the reed is applied at $A B$ the reed will vibrate in synchronism.

Consider this same reed, now in motion, to be moving also between a second set of electromagnet coils $G$, as shown at $B$ (fig. 1). As the reed moves up the flux in the upper coil will increase, thus producing an e. m. f. at the upper coil terminals, and the flux in the lower coil

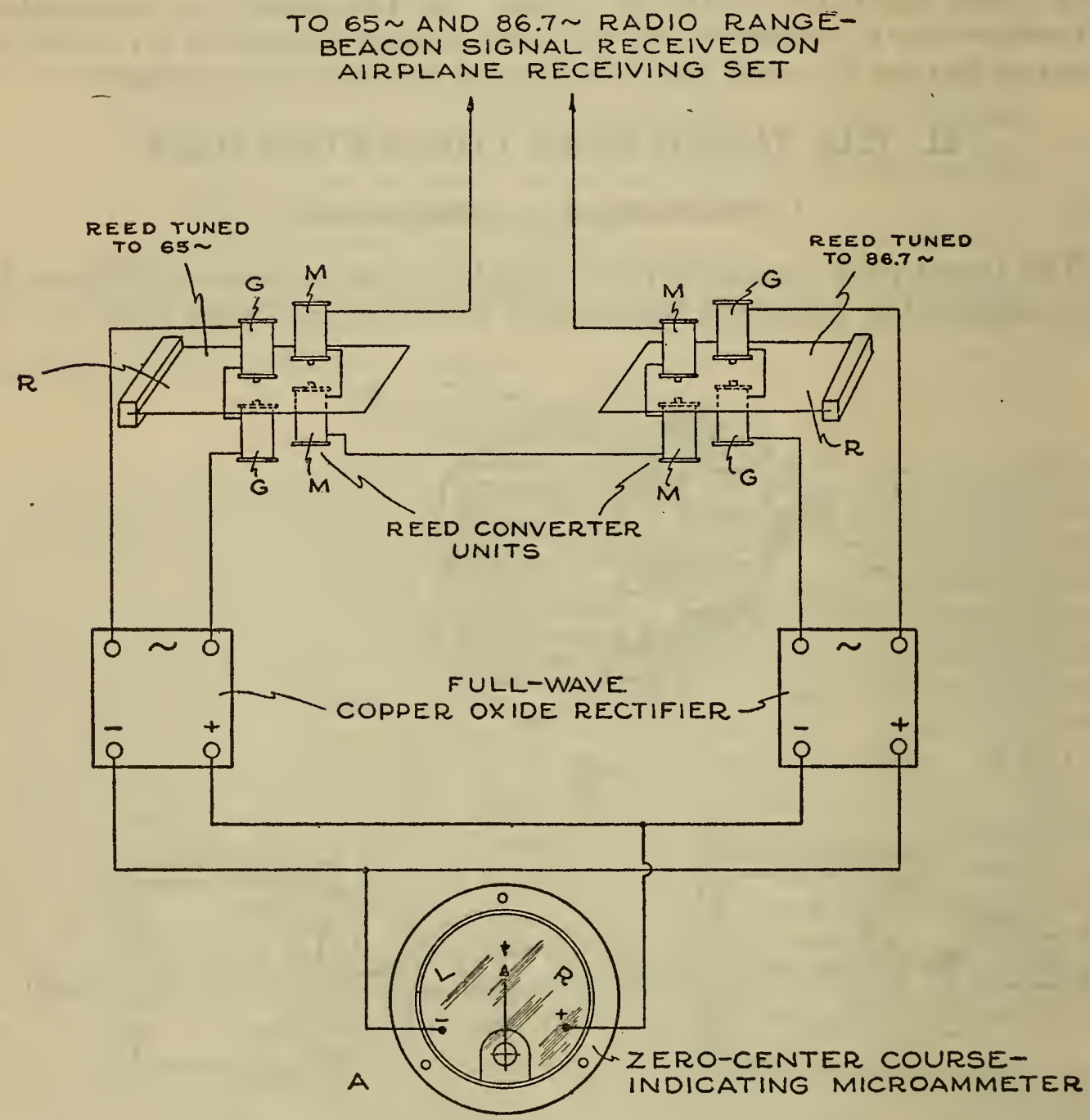

FIGURE 2.-The simplest form of circuit arrangement used with the tuned-reed converter

will decrease, thus producing an e. $\mathrm{m}$. $\mathrm{f}$. at the lower coil terminals. If connected in the proper polarity, these e. m. f.'s will add and a voltage will be produced at the terminals $C-D$. When the reed goes down, a voltage of opposite polarity is produced at $C-D$. Thus the vibrating reed produces an alternating-current voltage of the frequency of vibration of the reed.

The reed converter was made by combining the one reed $R$ as shown at $C$ (fig. 1) with the two sets of permanent magnets $T$ and $L$. One set of coils $M$ is supplied with the radiobeacon signal modulated at the frequency to which the reed is tuned, thus causing the reed to vibrate, 
and thereby generating in the other set of coils $G$ a voltage of the frequency of the vibrating reed. This reed converter, therefore, acts as a mechanical filter, allowing practically nothing but one frequency, that to which the reed is tuned, to pass through it.

In flight on a given radio-range beacon course, two units of the type shown in Figure 1, $C$ are used, the reed in one unit being tuned to, say, 65 cycles, with the reed in the second unit tuned to, say, 86.67 cycles. The outputs from the coils $G$ in each unit are rectified by means of oxide rectifiers and the rectified voltages applied in opposition to a zero-center microammeter, as shown in Figure 2. This tuned-reed converter unit is operated on the airplane by means of signals from the double-modulation type of radiobeacon, in which one carrier frequency is transmitted directively from two coil antennas oriented at right angles. The carrier radiated from one coil antenna is modulated at 65 cycles, the carrier radiated from the other coil antenna is modulated at 86.7 cycles. The course is along a line of direction in space where the two modulation frequencies are present in equal intensities. Off the course the intensity of one modulation frequency is greater than that of the other.

Thus when the airplane is on the course the 65 and 86.7 cycle received signals are of equal intensity and the d. c. output voltages from the two oxide rectifiers will be of equal amplitudes but of opposite polarity, and the course-indicating instrument will read zero. However, if the airplane deviates from the course, a greater strength of signal of one frequency than the other will be received, upsetting the balance, and the indicating-instrument needle will deflect an amount depending upon the degree of deviation from the course. Means for keeping the deflections of the indicating instrument in the same direction as the deviation of the airplane from the course will be discussed later.

\section{DETAILS OF DESIGN}

\section{(a) THE REED CONVERTER UNIT DESIGN}

The reed converter unit, as finally designed, is shown in detail in Figure 3. Figure 4 is a photograph of the unit. The unit is mounted on a bakelite base with plug connections so that it may readily be removed from its shock-proof base (not shown), so that a reed unit tuned to a different frequency may be inserted if desired. This plug-in feature also facilitates checking the reed calibration, as a spare unit may be easily inserted while the calibration check on the old unit is being made. The copper-oxide rectifier $\mathrm{O}$ is also arranged to plug in to the circuit. This rectifier, which is of the type used in a. c. indicating instruments, is mounted in a small bakelite case for protection, a lock nut and screw being employed for holding the case in place. Since the rectifier operates on the output of the reed converter, it can never be overloaded, as it is rated at 5 milliamperes, and the maximum possible input which occurs as the reeds bump the pole pieces, is about 500 microamperes.

The permanent magnets $T$ and $L$ are made from a chromium-nickel iron alloy known as 36 per cent "Cobaltcrom." They are magnetized with a polarity as indicated in Figure 3. Two are used to keep the driving and pick-up magnetic circuits separated to prevent coupling and to increase the sensitivity. The electromagnet coils $M$ and $G$ are similar to those used on the Western Electric type 509-W 
head telephones. The pick-up coils $G$ are connected in series in the proper polarity, and the reed driving coils $M$ are connected either in series or in parallel in the proper polarity, depending upon the impedance desired in order to match that of the receiving set output. The two pick-up coils are placed 1 inch from the base of the reed and the two driving coils eleven-sixteenths inch from the base.

The reed $R$ is made of an alloy known as Allegheny electric metal. It has a magnetic permeability as good as that of steel, is rust proof, and has a modulus of elasticity, which, although not entirely independent of temperature, is sufficiently so to allow of its use, especially with the broadness of tuning of the reed as used in this converter unit.

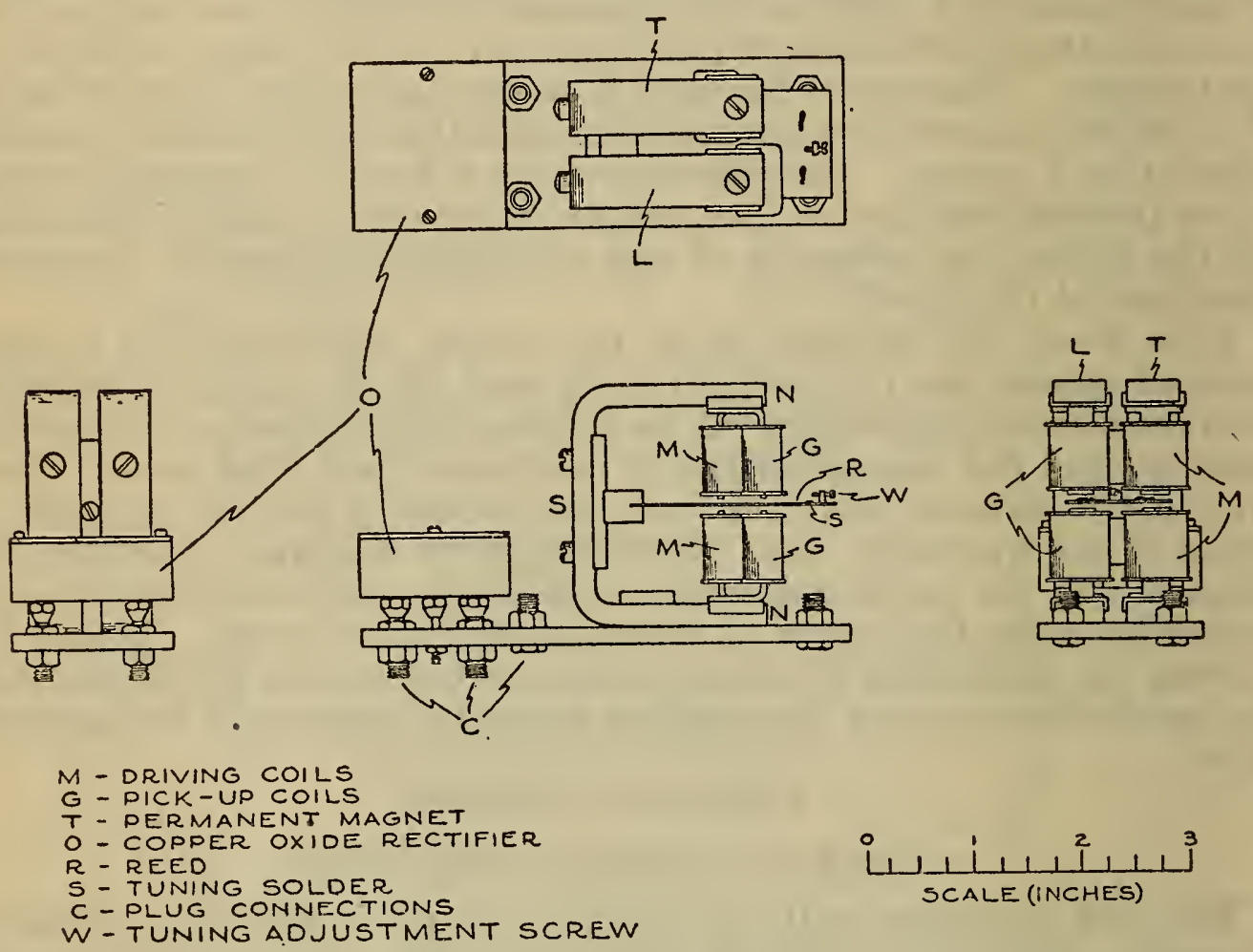

FIGURE 3.-Schematic diagram showing construction of tuned-reed converler unit with oxide rectifier

This material is noncorrosive in ordinary climates so that its weight does not change during use. Any change in weight will, of course, throw the reed out of tune. The 65 -cycle reed is 2 inches long, 1 inch wide, and 0.013 inch thick. The 86.66 -cycle reed is $1 \frac{3 / 4}{4}$ inches long with the other dimensions the same as above. The 108.3-cycle reed is the same thickness and width but $1 \frac{5}{8}$ inches long. The proper size and shape of a reed for a given frequency may be determined mathematically. ${ }^{2}$ The reeds are tuned approximately to the desired frequency by means of solder (S, fig. 3 ) on the end of the reed. The final tuning is done by adjusting screw $W$ (figs. 3 and 4), which is made to turn very tightly in its threaded socket so that it can not be moved except with a screw driver. The screw and mounting are of noncorrosive material. It allows of a variation of 1 per cent in the tuning of the reed.

2 G. L. Davies, Theory of Design and Calibration of Vibrating Reed Indicators for Radio Range Beacons, B. S. Journ. Research, 7 (RP338), p. 195; July, 1931. 


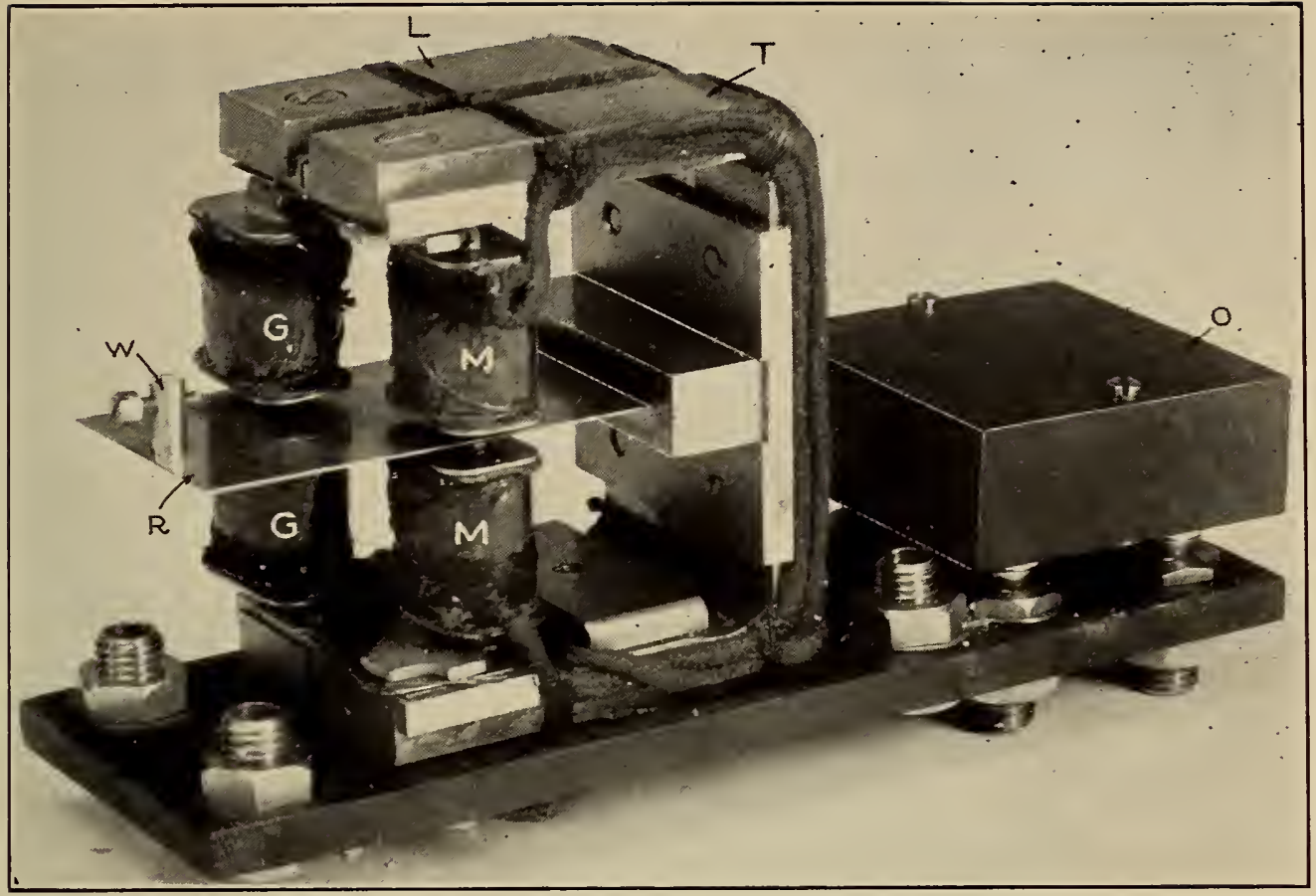

FIgURE 4.-A plug-in tuned-reed converter unit with plug-in oxide rectifier

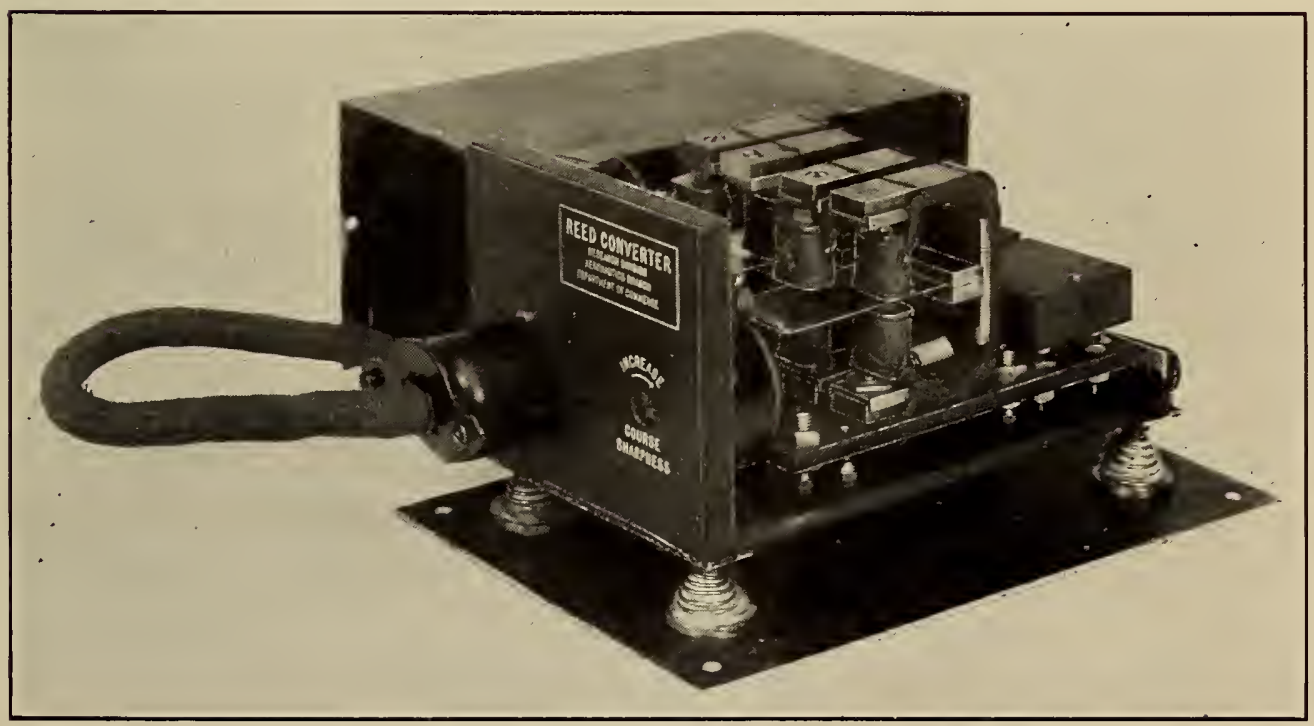

FIGURE 5.-Tuned reed converters in a 2-unit shock-proof mounting 
B. S. Journal of Research, RP336

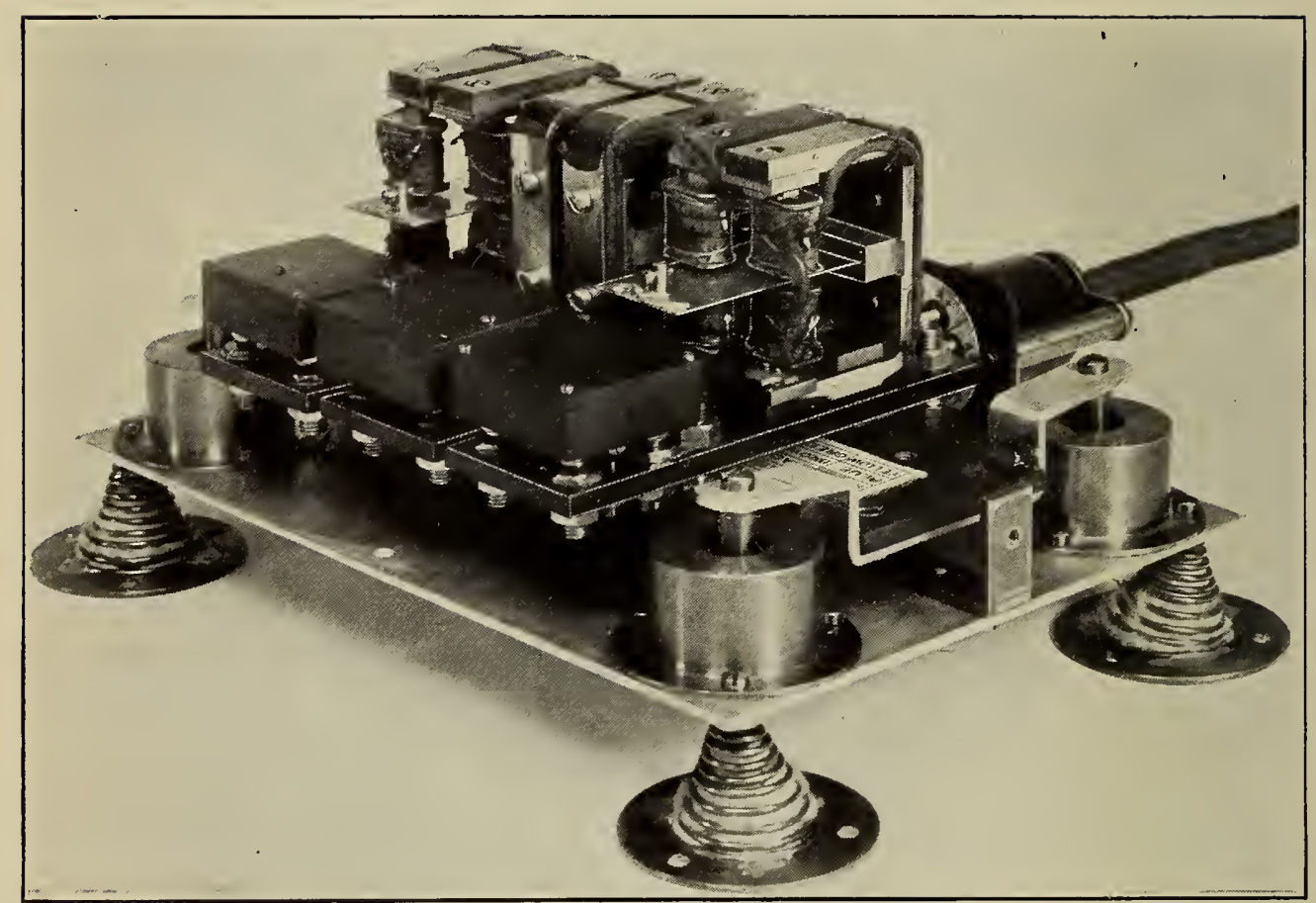

FIGURE 6.-Tuned reed converters in a 3-unit shock-proof mounting 
The gaps between the two pole pieces of the driving electromagnets $M$ control to a large degree the sensitivity of the indicator, while the gap between the pick-up coil pole pieces $G$ controls the reed damping as well as the sensitivity. For one set of reed converter units constructed, in which the two driving coils were connected in parallel, 0.5 volt input to these two coils gave a deflection of 200 microamperes on the course-indicating instrument. The sharpness of resonance was about 40 . (See Fig. 8.). In these units the gap between the electromagnet pole pieces varied between 0.04 and 0.06 inch.

At this point it might be well to mention the effect of direct coupling between the driving coils and the pick-up coils. Separate permanent magnets for the driving and pick-up coils solved the coupling problem as the two magnetic circuits are thus practically segregated. At the frequencies used, $65,86.7$, and 108.3 , the direct magnetic coupling between these coils, with the reed held stationary, is so small that it can not be measured on a 0-200 microammeter; this is with the normal input voltage to the reed converter unit which can not be exceeded due to the automatic volume-control feature used on the receiving set output. ${ }^{3}$ Should an excessive interfering signal of, say, 1,000 cycles be impressed on a converter unit, there is some appreciable coupling, but since two converter units are always used in series, and the output of the oxide rectifiers connected in opposing polarity, any effect from such a signal would be present in equal amounts in each converter unit and would, therefore, balance out. Furthermore, when used in a receiving circuit for reception from the simultaneous telephone and beacon type of signal, ${ }^{4}$ all frequencies above, say, 200 cycles are cut off from the reed converter input and are sent to the head telephones, and are, therefore, not present in the reed converter circuits.

\section{(b) THE REED-CONVERTER UNIT MOUNTING}

Since the least motion of the reeds in this type of reed converter induces a voltage in the pick-up coils, due to the small clearance between the reed and pole pieces, it is important that the reed be moved only by the driving coils and not by any mechanical vibration. The reed converter units are, therefore, placed on a base which in turn is mounted on conical springs, stuffed with cotton for damping, as shown in Figure 5. The 2-unit mounting shown in Figure 5 contains the plug terminals for receiving the reed converter units and the 7 -terminal socket for making the necessary external connections by means of a 7 -terminal plug. The 3 -unit mounting requires a 10 terminal plug connection. Such a mounting containing three converter units is shown in Figure 6. The resistance for adjusting the course sharpness (to be described later in this paper) is also placed on this mounting. It can only be adjusted by means of a screw driver, since when once set to give the desired course sharpness it should not be moved.

\section{(c) SENSITIVITY}

The gaps between the driving electromagnetic pole pieces are adjusted for each tuned-reed converter unit so that the three units will be of equal sensitivity. This adjustment is made at a normal course indicator operating current of, say, 200 microamperes. Figure

3 W. S. Hinman, jr., Automatic Volume Control for Aircraft Radioreceivers, B. S. Jour. Research, $y$

(RP330), p. 37; July, 1931 1 F. Kear and G. H. Wintermute, A Simultaneous Radiotelephone and Visual Range Beacon for the Airways, B. S. Jour. Research. This will appear in the August issue. 
7 shows the sensitivity curves for the three unit combinations. The a. c. input voltage was measured across two units in series, as they are used in this way in practice. The two driving coils in each unit were connected in parallel. In the region of operation of the reeds, that is, 100 to 300 microamperes, a linear relation exists between the input voltage and output current, and the slopes of the curves are about the same, which feature provides true course deviation indications as the relative value of the input voltage varies. The power input on one frequency to the two reed converters in series is about 1.0 milliwatt when an output current of 200 microamperes is obtained. This

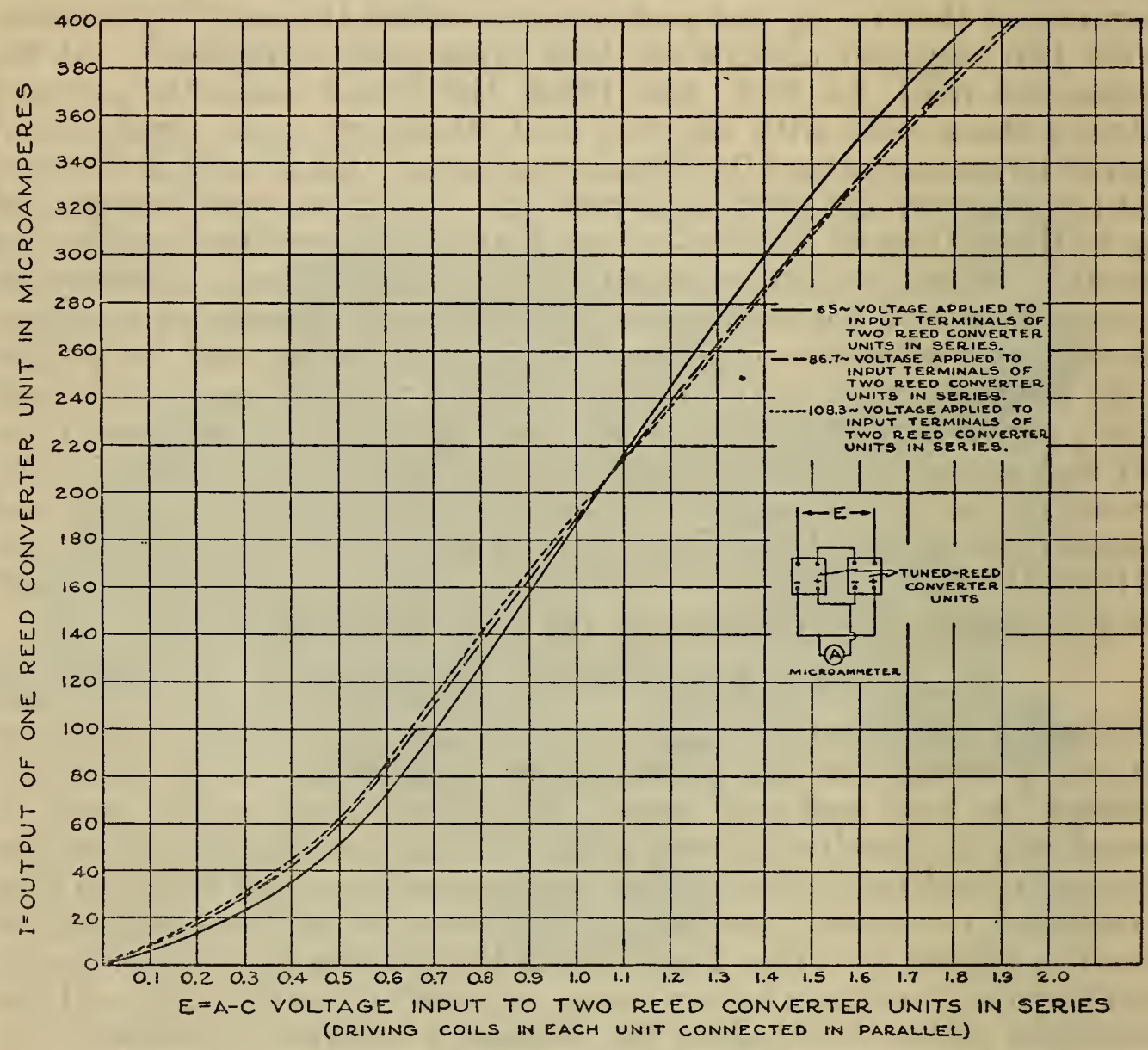

Figure 7.-Sensitivity characteristics for the 65-86.7 cycle, 65-108.3 cycle, and 86.7-108.3 cycle-reed converter course indicators

sensitivity, which is about equivalent to that of the ordinary tunedreed indicator, has been obtained with over twice the amount of damping in the reeds. The advantage of this increased damping is discussed under $(d)$ Sharpness of resonance.

\section{(d) SHARPNESS OF RESONANCE}

While the tuned-reed converter is about equal in sensitivity to that of the tuned-reed indicator, the amount of damping possible at this sensitivity is over twice as great. This damping, a large proportion of which is caused by the load introduced by the pick-up coils, is, of course, an advantage, since the modulation frequencies at the beacon need not be held to the accurancy required for the tuned-reed indicator. 
The damping is so proportioned that the output from the three reed converters will not change appreciably even though the frequency varies as much as \pm 1 per cent. The resonance curves for the three reed converter units are shown in Figure 8 . Since the three frequencies of modulation at the radio range beacon are obtained in most cases from three generators with 6,8 , and 10 poles, respectively, and with a common shaft connected to a synchronous motor driven from the 60 -cycle line, the three frequencies must vary in the

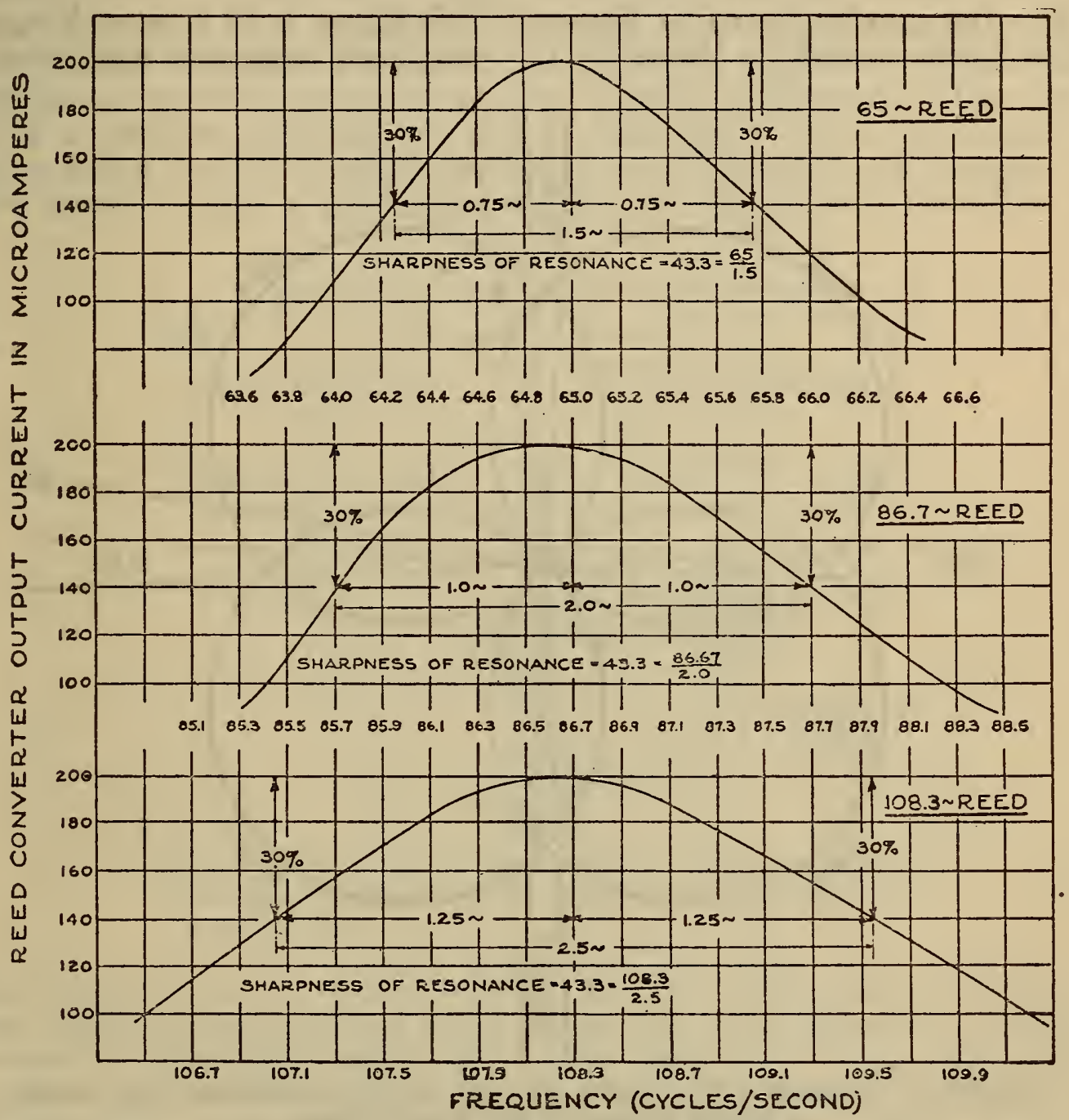

FIGURE 8.-Resonance curves for the three reeds in the reed-converter units, showing effect of correctly proportioning the damping to keep converter outputs the same with the same percentage change in frequency

ratio of $6: 8: 10$. Therefore, if a 0.75 -cycle variation occurs in the 65 -cycle frequency, a 1.0-cycle variation will occur in the 86.7-cycle frequency and a 1.25-cycle variation will occur in the 108.3-cycle frequency. From the graphs in Figure 8 it will be seen that for such a variation in each frequency, each reed converter output drops by the same amount; that is, 30 per cent, or from 200 microamperes to 140 microamperes. Since the relative outputs of the reed converters do not change, no apparent shift in course is caused by a variation in the 60-cycle power line frequency by as much as \pm 1 per cent. A more conservative figure would be \pm 0.75 per cent, however, since 
the resonance curves for a given reed converter may change slightly with time due to aging of the permanent magnets, etc.

A convenient method for expressing the sharpness of resonance of a tuned reed by a simple numeral has been adopted:

Sharpness of resonance $=\frac{\text { Resonance frequency in cycles }}{\text { Band width in cycles at } 30 \text { per cent drop in }}$ converter output from that at resonance

From the graphs shown in Figure 8, this figure is 43.3 in each case. This figure should be the same for each reed converter unit when-

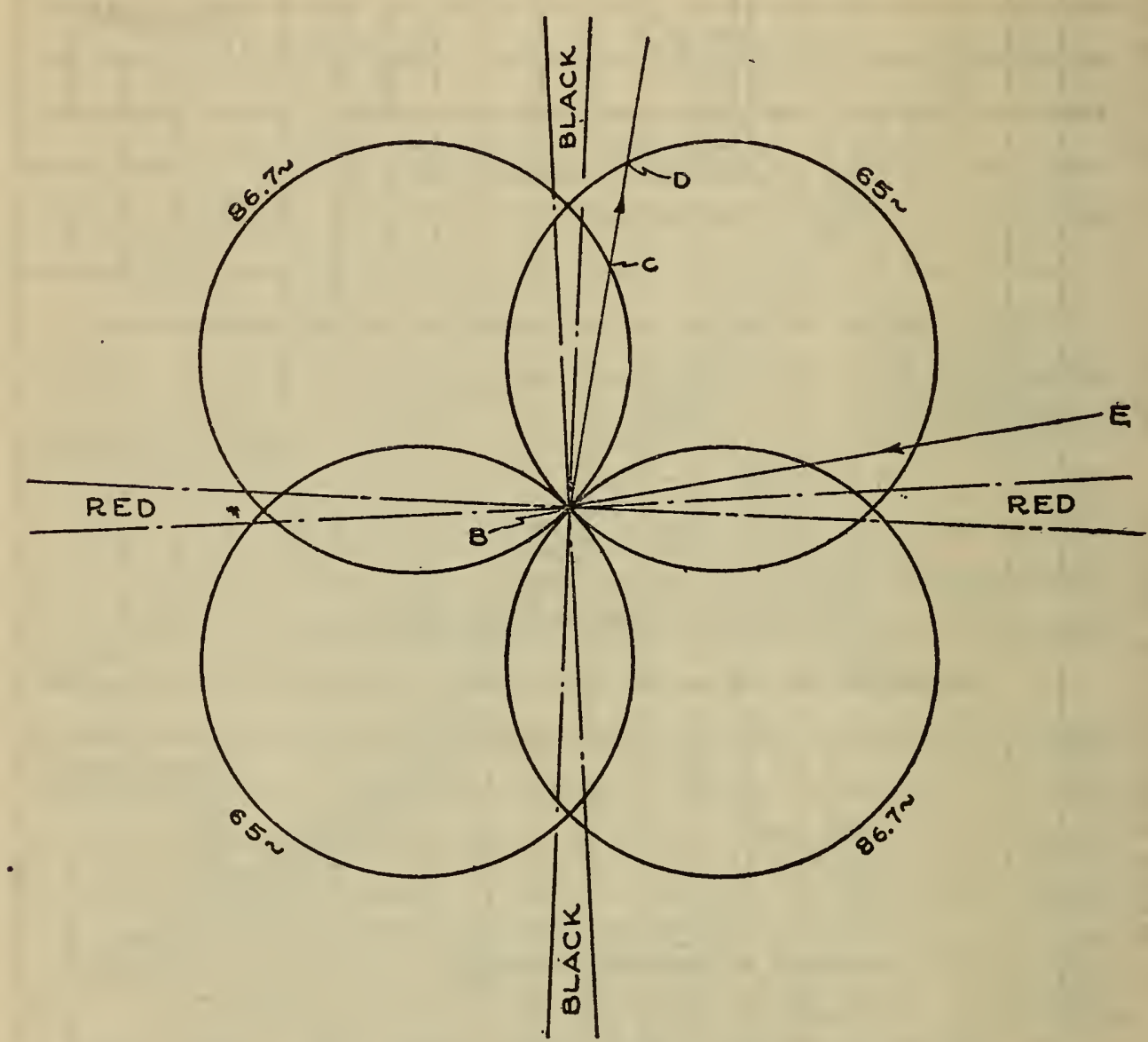

FIGURE 9.-Space pattern for the 4-course double modulation radio range beacon giving red and black courses

ever two units are used together, as they always are in practice. For the standard tuned-reed indicator (not the reed-converter type), this figure runs around 90.

\section{THE COURSE-SELECTOR SWITCH, DEVIOMETER, VOL- UME INDICATOR, AND COURSE SHARPNESS CONTROL}

\section{REED CONVERTER AS APPLIED TO A 4-COURSE RADIO RANGE BEACON}

In order to show the application of the reed converter to the radio beacon courses, a typical space pattern for a 4-course radio range beacon with red and black courses is shown in Figure 9. The radio range is located at $B$. Modulation frequencies of 65 -cycle and 86.7- 
cycle are used on these courses. It is evident that the simple circuit arrangement shown in Figure 2 makes the reed converter applicable to but one direction of flight on each of these courses, if the needle of the zero-center indicating instrument $A$ is to deflect in the same direction as the deviation of the airplane from the course. Thus when going "from" the beacon on a black course, if the airplane deviates to the right and flies along some course such as $B D$, the 65 -cycle signal will predominate by an amount proportional to $C D$, as shown in Figure 9 , and since the + side of the oxide rectifier in the 65 -cycle reed converter unit in Figure 2 is connected to the + side of the zero-center indicating instrument, the needle will deflect to the right. (Such instruments are wired to give a needle deflection to the right with a positive potential on the + terminal.) In a like manner, when going "to" the beacon on a red course, a deviation to the right of the course causes a predominant 65-cycle signal and, therefore, a

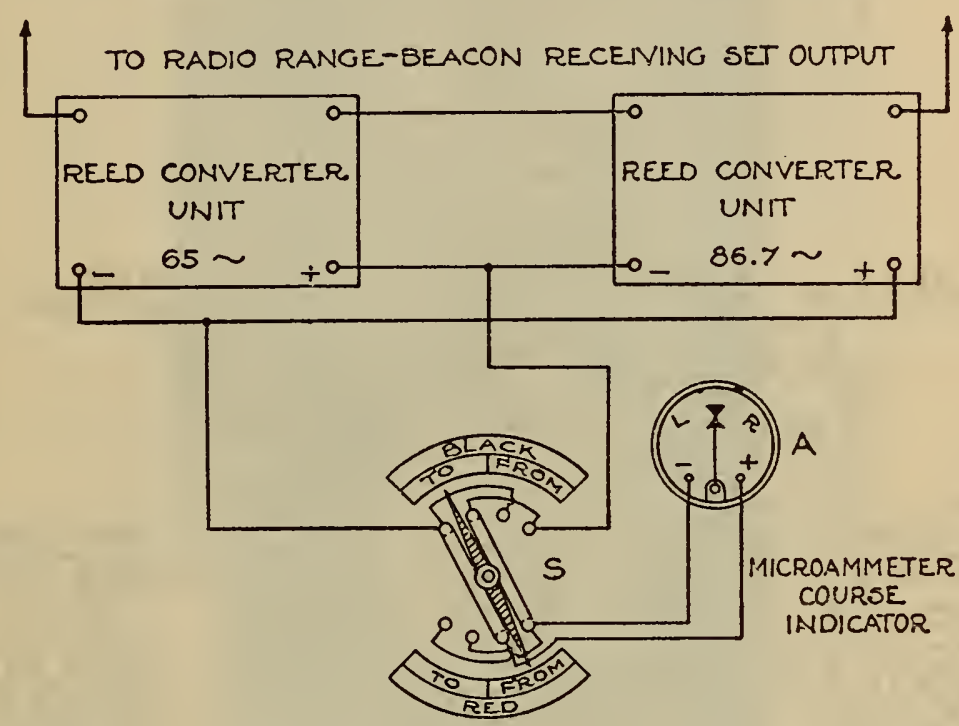

FIGURE 10.-Use of reversing switch in reed-converter outputs in order to adapt converter to the 4-course radio range beacon

right-hand deflection of the indicator needle. The needle deflections are in the wrong direction when flying "to" the beacon on a black course or "from" the beacon on a red course. A simple method for overcoming this difficulty is to put a reversing switch between the oxide rectifier outputs and the zero-center indicating instrument, as shown in Figure 10.

A color system is chosen such that the indicator needle deflection is always in the same direction as the deviation of the airplane from the course when flying in either direction on either the red or black courses. If the circuits in Figure 10 are checked through in conjunction with Figure 9, it will be found that if the reversing switch $S$ is set to any desired direction of flight on either of the courses (red or black) and the airplane deviates, say, to the right, the resultant polarity of the voltage impressed at the terminals of indicating instrument $A$ will cause it to deflect to the right. In Figure 10 the pointers on switch $S$ are set for flying either "to" the beacon on a black course or "from" the beacon on a red course. 
2. USE OF THE DEVIOMETER, VOLUME INDICATOR, AND COURSESHARPNESS CONTROL

(a) THE DEVIOMETER

Before going into the application of the reed converter to the 12course beacon, the use of the deviometer, volume indicator, and course sharpness control will be discussed. The deviometer is used with the reed converter in the same way as with the tuned reed indicator, its function being to enable a pilot to fly along an off-course route, yet allowing the zero-center indicating instrument to read zero when the airplane is on this off-course route. Any deviations from this route are thus indicated in the usual way. Such off-course routes

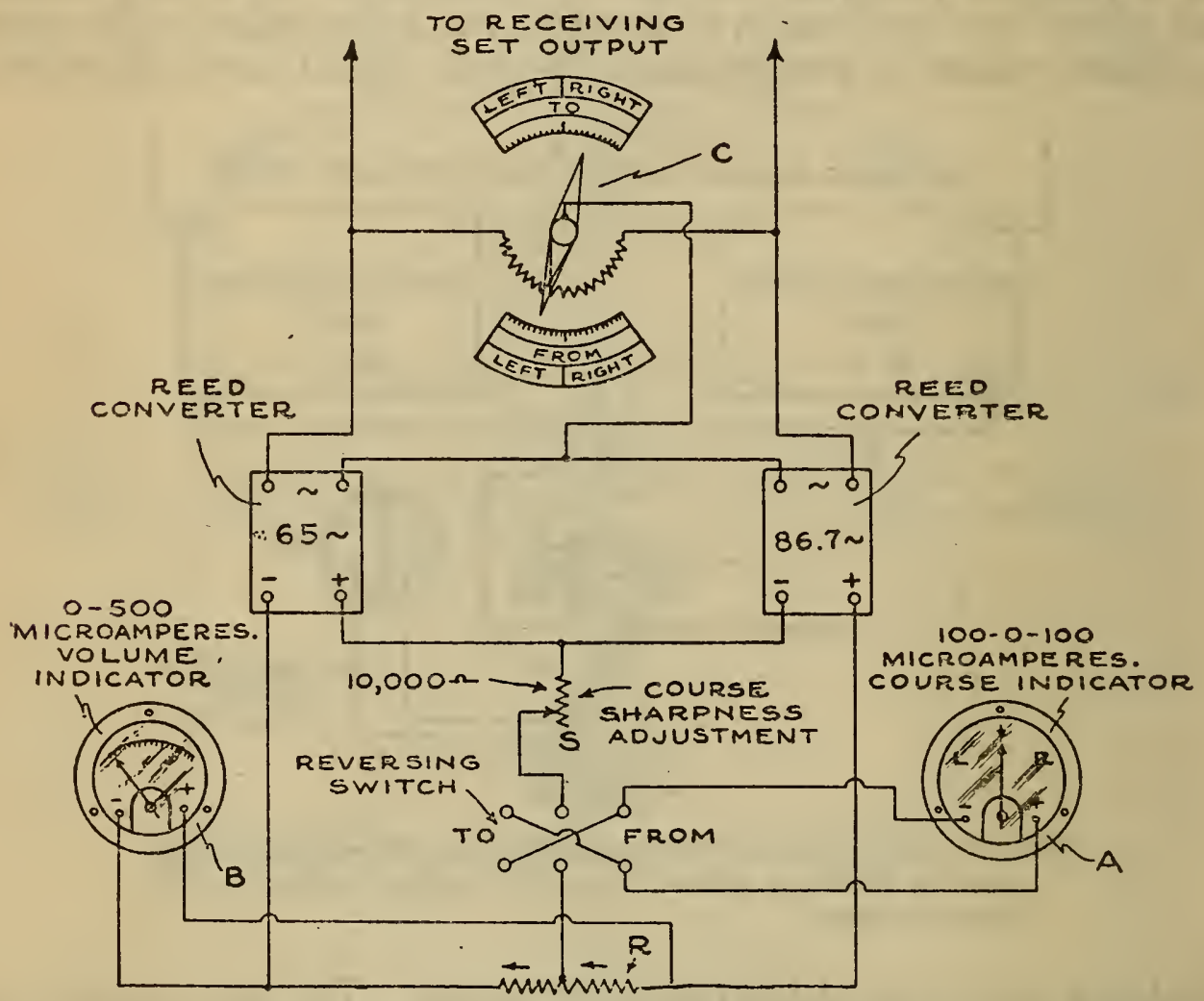

FIGURE 11.- Simple deviometer and volume indicator circuit arrangements for using the reed converters on a red course

may be flown along any line making an angle of up to $15^{\circ}$ on either side of the equisignal course. The deviometer shown at $C$ (fig. 11) consists of a 10,000 to $20,000 \mathrm{ohm}$ resistor shunted across the two converter driving coils, with the sliding contact connected to the common connection between the two sets of driving coils. The arrangement at $C$ (fig. 11) is for a red course only. Such a double pointer and wording arrangement is necessary, since the direction of movement of the sliding contact on the resistor reverses for a reversal of the direction of flight. Referring to Figure 9, assume a pilot desired to fly along an off-course line, such as $B E$, on the right of the red course going "to" the beacon. In order to keep the zero-center course indicating instrument from deflecting to the right due to an increase of the 65-cycle signal along this route, the effective sensitivity of the 65cycle converter driving coils is reduced by lowering the deviometer shunting resistance across these coils. This is done by moving one of 
B. S. Journal of Research, RP336

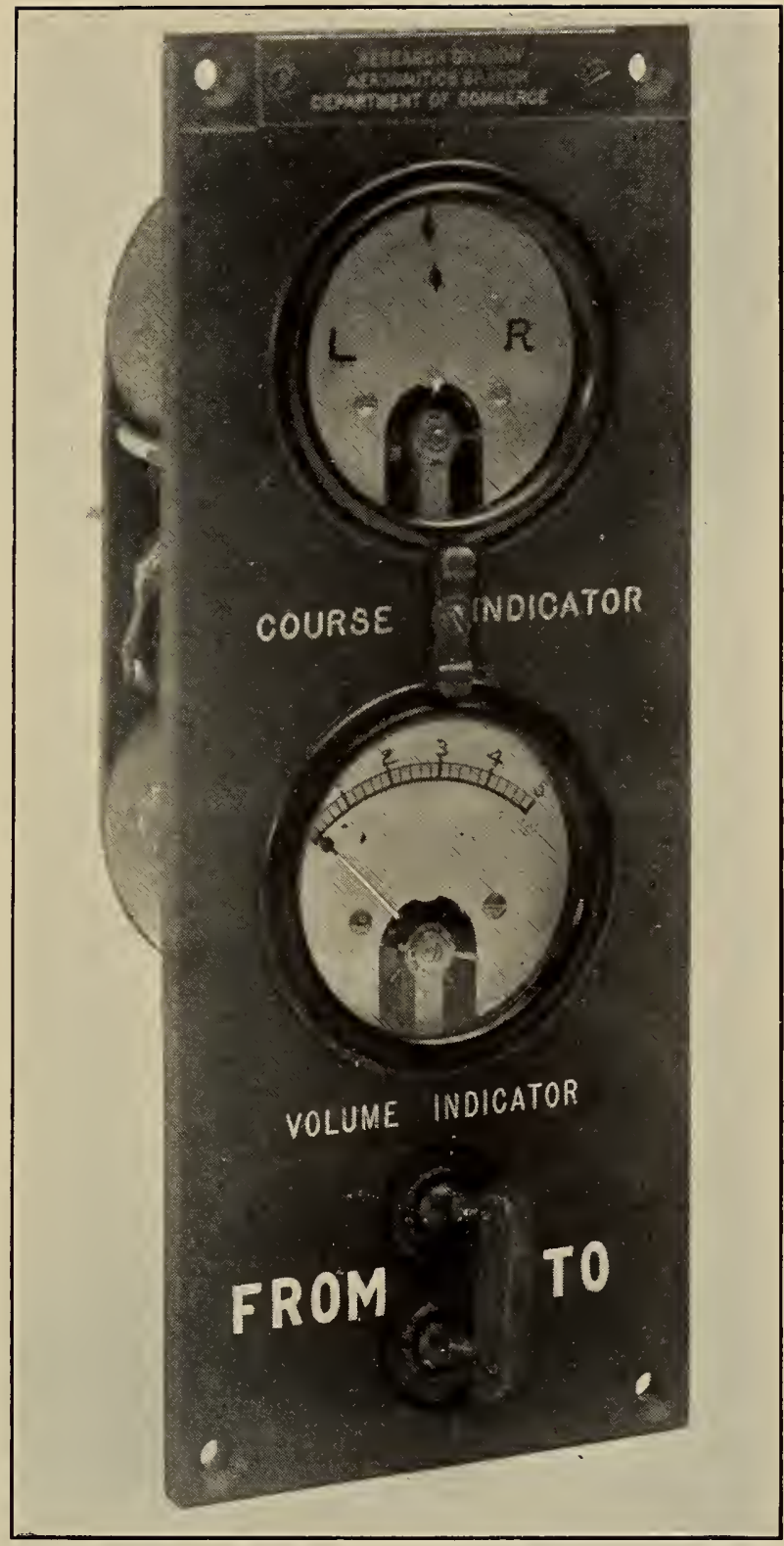

FIGURE 12.-Course and volume indicating instruments with reversing switch for use with reed converter on a red, brown, or yellow radio-beacon course 
B. S. Journal of Research, RP336

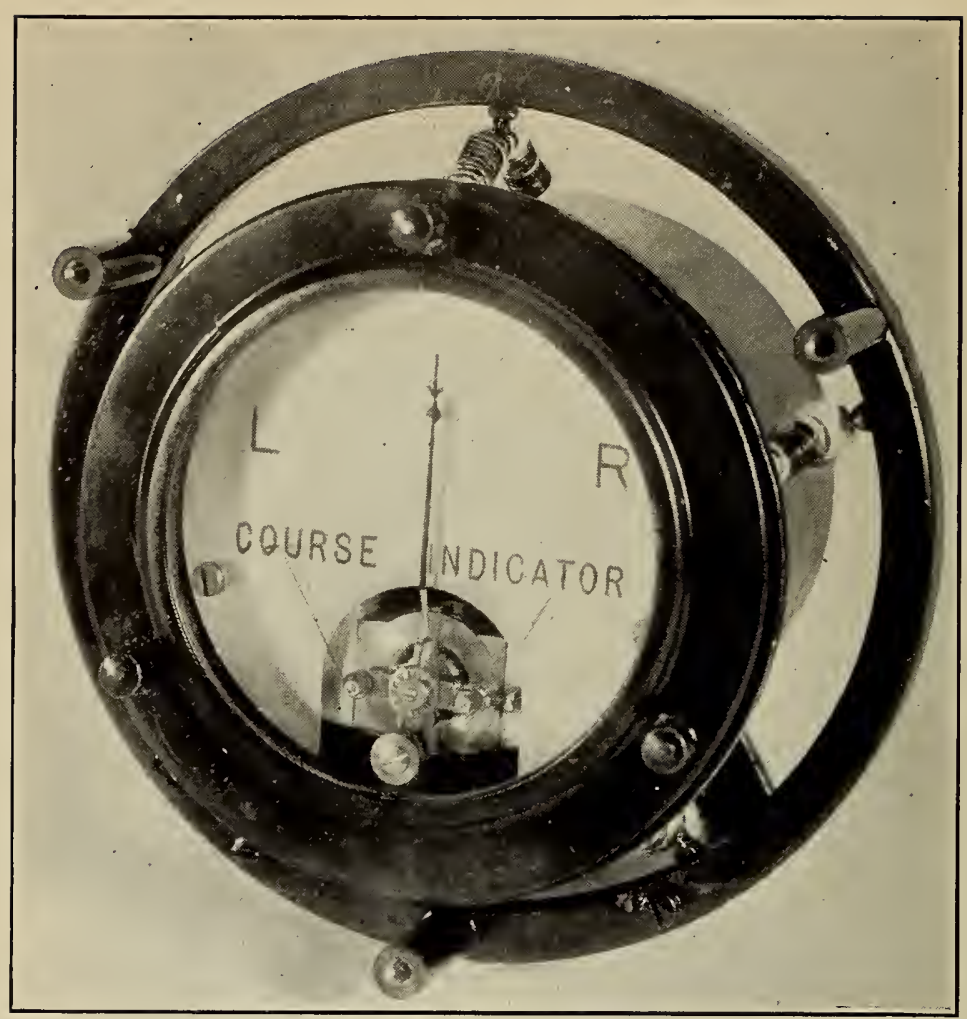

FIGURE 13.- Reed converter-course indicating microammeter in plug-in shock-proof mounting

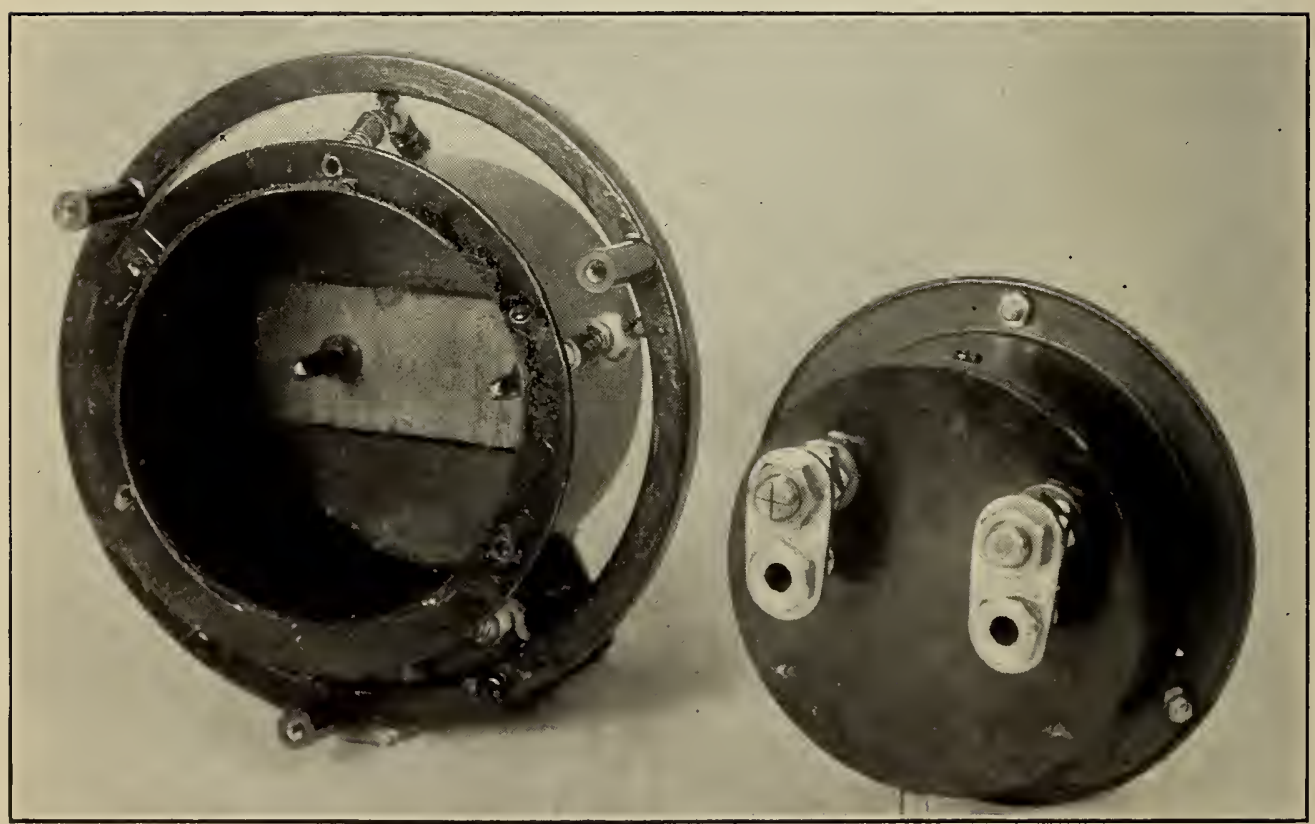

FIGURE 14.-Reed converter-course indicating microammeter showing plug-in feature and shock-proof mounting 
the deviometer pointers (fig. 11) to point, on the "To" scale, to the segment marked "Right." The amount of movement of deviometer $C$ should be sufficient to reduce the indicating instrument deflection at $A$ to the zero center when the airplane is on the new course, $B E$. The application of the deviometer and reed converter to all courses of the 4 or 12 course beacon will be discussed below.

\section{(b) THE VOLUME INDICATOR}

One seeming disadvantage of the reed-converter type of beacon course indicator is that a null method of course indication is used, which means that the beacon signal may be off, or the receiving set not functioning, yet the course indicating needle will read "on course." This can not happen with the tuned-reed indicator as the moving reeds are always visible, indicating the presence of a beacon signal as well as the volume output of the receiving set.

A method of overcoming this difficulty is to use a second indicating instrument with a range of about 0-500 microamperes as a volume indicator. The method of connecting this instrument in the reedconverter circuit is shown in Figure 11 at $B$. A center-tap resistor $R$ of about $100 \mathrm{ohms}$ is so connected to the oxide rectifier outputs that the $R I$ drops across this resistance are additive so that both rectifier outputs deflect the needle of instrument $B$ in the same direction. Such a system gives a positive indication that both modulation signals from the beacon are present in the reed-converter circuits. Furthermore, instrument $B$ indicates the volume of signal output from the receiving set; thus a beacon signal may be tuned in by watching instrument $B$ until it reads a maximum as the receiving set is tuned. A normal reading for $B$ is about 250 microamperes. This output level may be held in flight either by an occasional adjustment of the volume control on the receiving set or by one adjustment in the automatic volume control unit, if such a unit is used.

There are several advantages in locating the volume-indicating instrument in the position in the circuit, as shown in Figure 11, and not in the output of the receiving set or elsewhere in the receiving set circuits. First, it is located at the very end of the whole receivingcircuit arrangement, including the reed-converter circuits, so that it will indicate a malfunctioning of any part of the complete beacon receiving system, and, secondly, instrument $B$ is operated only by the tuned-reed outputs so that the mechanically tuned selectivity of the reeds prevents any interfering signal from operating it.

Figure 12 is a photograph of a panel containing the course and volume indicating instruments and a reversing switch. The reversing switch is of the snap type, and may be either thrown toward the word "From" (when flying "from" the beacon) or to the word "To" (when flying "to" the beacon). The panel is wired for use when flying in either direction on a red course. It may also be used on a brown or yellow course with the proper reed converters. By reversing the leads to the course-indicating instrument, this panel may be used on a black, blue, or green course. These new courses will be discussed below.

The two indicating instruments in figure 12 plug into iron cans supported on the panel, making the necessary electrical connections. $60869-31-11$ 
The cans are iron to keep strong magnetic fields from the instruments from affecting the airplane's magnetic compass. The lower can contains the resistance $R$. (Fig. 11.)

As the indicating instruments are the most fragile part of the reedconverter apparatus, it is preferable to mount them on springs. Such a spring mounting for the course indicating microammeter is shown in Figure 13. Figure 14 shows a rear view of the instrument removed from its iron case holder, showing the electrical plug connections. In case an instrument is found to be defective a new one may be immediately plugged into the holder.

\section{(c) THE COURSE-SHARPNESS CONTROL}

Unlike the tuned-reed indicator the course-sharpness indication given by the reed converter is a function of the beacon signal level delivered to it or to the course-indicating instrument. An unbalance in the course indicator with two strong output signals from the reed converter, gives a much greater deflection and, consequently, an apparently sharper course. The degree of sharpness may be set to suit the pilot, either by adjusting the automatic volume control on the receiving set (or hand volume control) to change the signal level delivered to the converter or, assuming a given signal level, the course sharpness may be controlled to a large extent by means of a 10,000 ohm resistance $S$ (fig. 11), which is connected in series with the course-indicating instrument $A$. The value of this resistance depends upon the sensitivity of the instrument used. By decreasing this resistance or increasing the beacon signal delivered to the reed converter, an apparent sharpening of the beacon course is brought about. However, in so doing, the useful portion of the beacon space pattern is reduced, since a deviation of only $10^{\circ}$ from the course may throw a 100-0-100 microampere course indicator off scale with a strong beacon signal level impressed on the reed converter, while with a weak signal and broad course indications, the needle will stay on scale for a $45^{\circ}$ deviation from the course. In other words, the useful width of the beacon space pattern may be increased at a sacrifice of course sharpness. An advantage of the tuned-reed indicator over the reed converter is that it gives useful course indications up to the full width of the beacon space pattern. A method of partially overcoming this disadvantage in the reed converter is to have a course-indicating instrument with a more open scalc. Such instruments are now made with $270^{\circ}$ of scale in place of the customary $100^{\circ}$.

The effect of the apparent variation of the course sharpness with beacon signal strength input to the reed converter is shown in Figure 15. The data for these curves were taken on the National Bureau of Standards' visual type beacon at College Park, Md. The test circuit arrangement used is as shown in Figure 15. It will be noted that with a beacon signal input voltage to the reed convertors of 3.5 volts, the effective width of the beacon space pattern is only $10^{\circ}$ when using a 100-0-100 microammeter and about $24^{\circ}$ when using a 250-0-250 microammeter, while with a voltage input of 1.5 volts the width is $27^{\circ}$ with the 100-0-100 instrument and the full width of $90^{\circ}$ with the 250-0-250 instrument. Thus, when using a 100-0-100 microammeter and an input voltage of 3.5 volts, the pilot can not deviate 


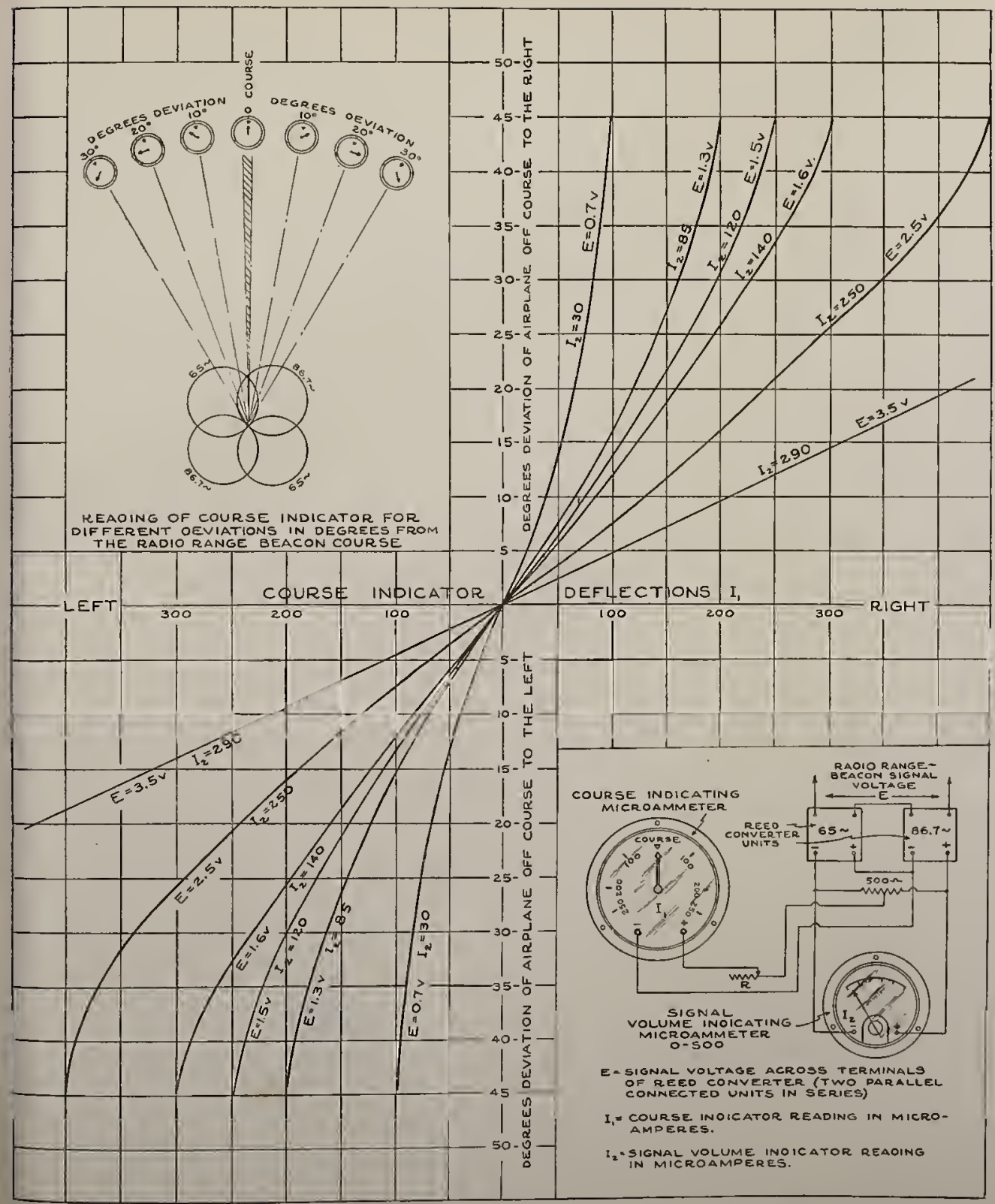

FIGURE 15.-Course indicator deflections as airplane deviates from the course using different beacon signal levels impressed on the reed converter, illustrating course sharpness variations with signal level

60082-31. (Face p. 100.) 
more than $\pm 5^{\circ}$ from the true course without losing an indication of the degree of further deviation.

Satisfactory course indication for most purposes is given by using a signal volume level $I_{2}$ of 250 microamperes, which is one-half-scale deflection. This signal level when used with a 250-0-250 microammeter course indicator, makes possible a deviation from the course of $\pm 21^{\circ}$, with correct course-deviation indications throughout this range.

Instead of varying the voltage $E$ as shown, it may be held at some value such as 3.5 volts, and a similar set of graphs obtained by varying the resistance $R$ (fig. 15), in series with the course-indicating microammeter.

From the above it will be seen that the reed converter used in the circuits as shown is very flexible in its use and may be adjusted at will (by the pilot if desired) to suit the conditions of use.

\section{REED CONVERTER APPLIED TO 4- OR 12-COURSE BEACON}

\section{(a) TWO-UNIT PLUG-IN ARRANGEMENT}

In order to explain the application of the reed converter to a multiplicity of courses, the polar diagram for a 12-course beacon is shown in Figure 16. As far as the modulation frequencies and course colors are concerned, this diagram may represent three 4-course beacons also; red and black courses being on one, brown and blue courses on a second, and yellow and green courses on a third. The colors indicate the courses or zones where two of the frequencies of modulation are present in equal amounts. This color scheme has been chosen to simplify the use of the 12 -course tuned reed indicator, ${ }^{5}$ and is equally effective for simplifying the use of the reed-converters. The pilot's map, if he requires one, should show the radiobeacon courses in their proper color.

One method of applying the reed converters for use on any course of a 4- or 12-course beacon is shown in Figure 17. Here a double reedconverter plug-in mounting, as shown in Figure 5, is provided at $A-B$, into which any two converter units may be quickly plugged. With a given set of two units, the pilot may use four of the courses of a 12-course beacon or the four courses of a 4-course beacon. By putting a 65 -cycle converter in at $A$ and 86.7-cycle converter at $B$, a red or black course may be flown. By putting a 108.3-cycle converter in place of the 86.7-cycle unit in $B$, a brown or blue course may be flown, or by putting an 86.7-cycle converter in at $A$ and leaving the 108.3-cycle unit in at $B$, a yellow or green course may be flown. For example, let us assume that it is desired to fly an airplane over a yellow radiobeacon course. Referring to Figure 17, the chart on the right shows that for a yellow course an 86.7-cycle converter should be plugged in at $A$ and a 108.3-cycle converter at $B$. This may be done by the ground personnel. Now, let the direction of flight be "from" the beacon and let us assume that the pilot wishes to fly along the line $O D$ (fig. 16,) slightly to the right of the course (airplanes going in the opposite direction flying a little to their right to avoid collision). The deviometer pointer, pointing to the yellow scale, is turned to point toward the word "Right" on the "From"

\footnotetext{
- See second paper of foot note, p. 148.
} 
scale. This increases the sensitivity of the 86.7-cycle reed at $A$ and decreases the sensitivity of the 108.3 -cycle reed at $B$. It will be noted from Figure 16 when going "from" the beacon (the beacon being at the intersection of all courses at $O$ ) on a yellow course, when deviating to the right along the line $O D$, the 108.3-cycle signal becomes greater than the 86.7-cycle signal by an amount proportional to $E F$, so it must be cut down to make them equal. This is what occurs when the

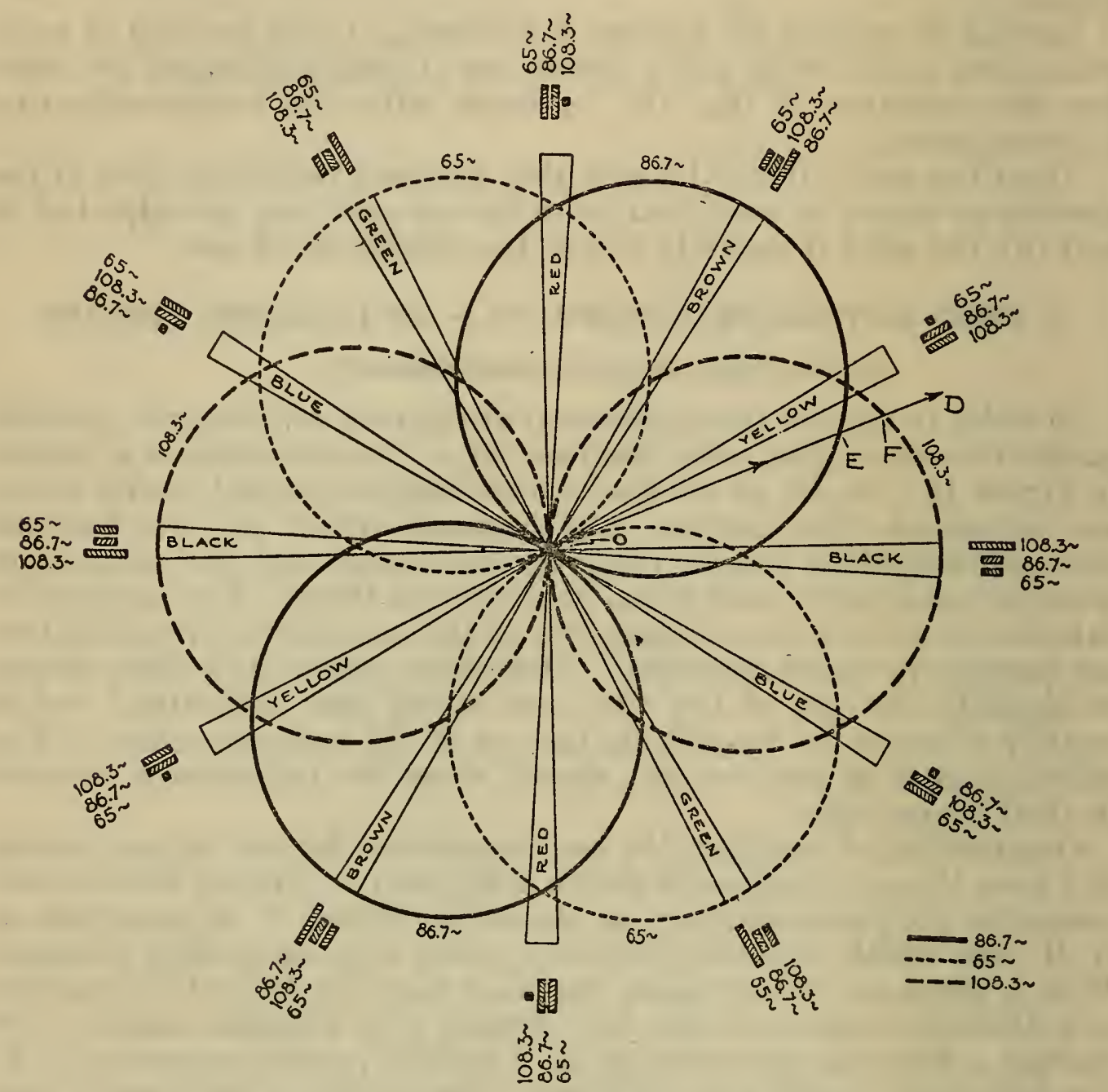

FIGURE 16.-The 12-course radio range-beacon transmission characteristic

The colors indicate the courses where two modulation frequencies are of equal strength and reedconverter outputs are equal, producing an on-course reading on the course indicator.

deviometer pointer is moved as stated above, since a lower resistance is shunted across $B$ or the 108.3 -cycle reed, thus cutting down its sensitivity, and a higher resistance is shunted across $A$, the 86.7 -cycle reed, thus increasing its sensitivity.

The course-selector switch must also be set so that the pointer on the yellow scale points to "From." In this position it will be noted that the positive output of the 108.3-cycle converter at $B$ is connected to the + side of the course-indicating instrument, thus causing it to deflect to the right, as the 108.3-cycle signal predominates over the 86.7 -cycle signal. From Figure 16, it will be seen that when flying on the yellow course "from" the beacon that the 108.3-cycle signal predominates when the airplane deviates to the right. Thus the course 
indicator needle deflects in the direction of deviation of the airplane from the course.

By taking any course and any desired direction of flight and using Figures 16 and 17, it can be shown as above that when the proper two

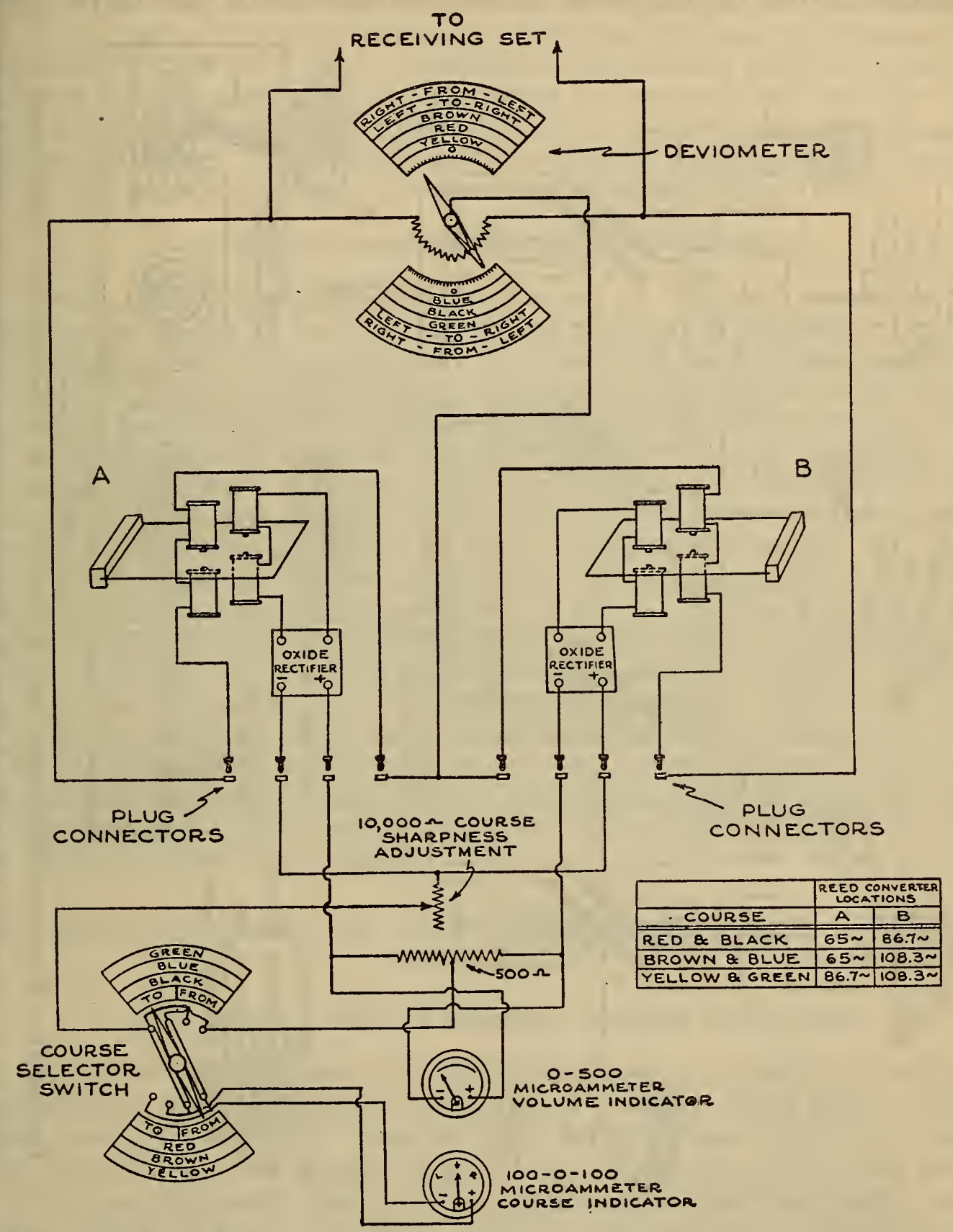

FIGURE 17.-Deviometer and course-selector switch with color system and converter plug-in arrangement for adapting the reed converter for use in any direction of flight on any course of a 4- or 12-course beacon.

reed-converter units are plugged into circuit and the deviometer and course-selector switch set properly, correct course-deviation indications will be obtained.

The 2-unit plug-in converter arrangement shown in Figure 17 is applicable where a given airplane is flown over the routes of 4-course beacons with the same colored courses or from one 12-course beacon 
to another on the same color and $90^{\circ}$ color routes; for example, airplanes flying on a transcontinental air route or on a north and south route would probably use the same color course all the way, in which case this circuit arrangement would be useful. Should the airplane fly other routes, the proper set of reed-converter units may be plugged

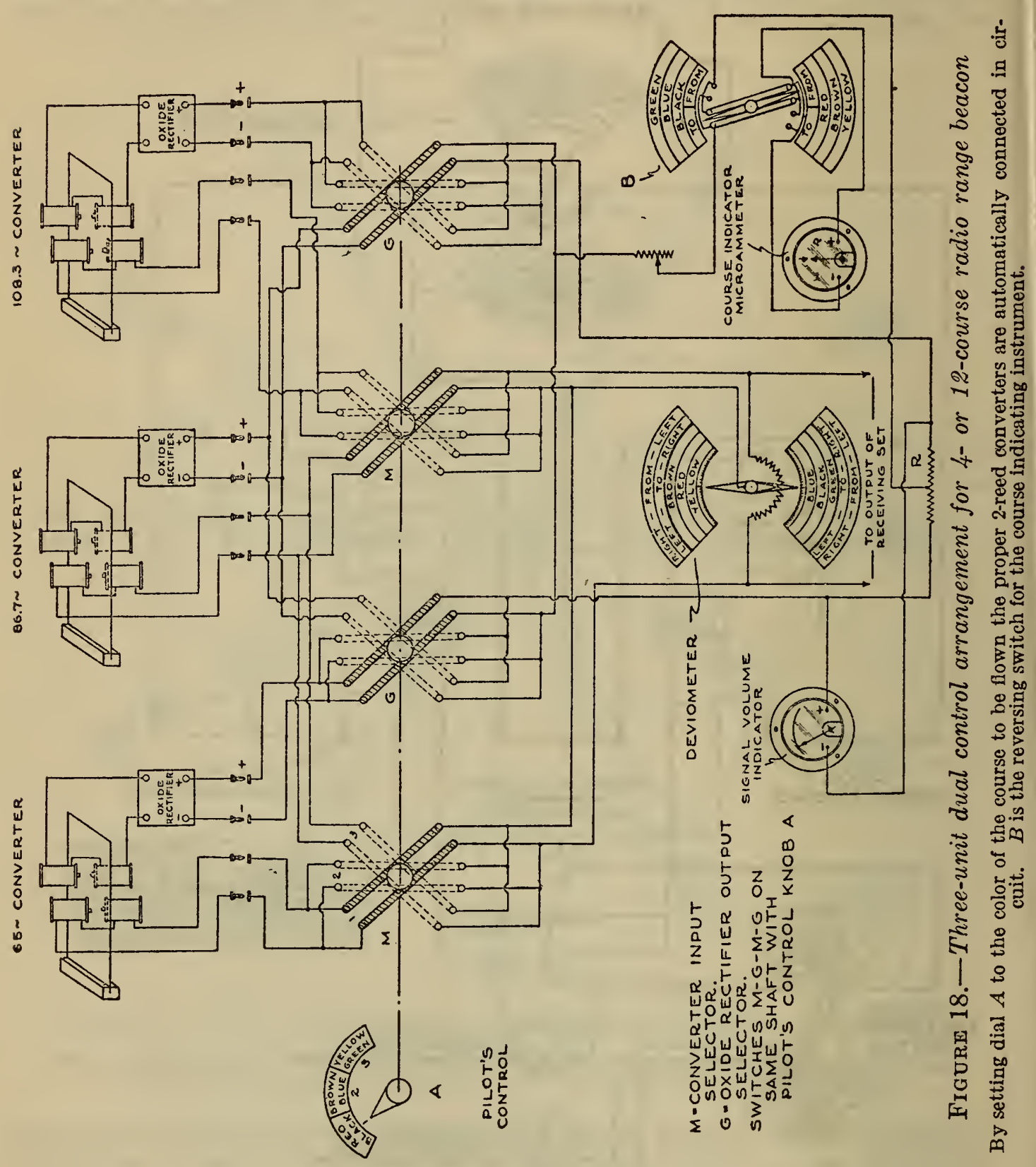

in, thereby adapting the course indicator for use on these routes. An advantage of this circuit with plug-in arrangement is that a simple form of course-selector switch may be used as shown in Figure 17.

(b) THREE-UNIT DUAL-CONTROL ARRANGEMENT

(b) In order to make a single reed-converter installation useful on any course of a 4 or 12-course beacon at all times without any plugging in of reed-converter units by the pilot or ground personnel, a 3-unit circuit arrangement shown in Figure 18 has been worked out. The selector or reversing switch and deviometer shown in Figure 17 have 
been retained, but a second selector switch containing the $\operatorname{dial} A$ and switches $M-G-M-G$ on a common shaft has been added. The three converter units are left permanently in circuit, although they are still of the plug-in type so as to be quickly removed for replacement if necessary. The $\operatorname{dial} A$ when set to the color of the course the pilot desires to fly, connects the proper 2-reed converter units in circuit by means of selector switches $M-G-M-G$. Switches $M$ connect the proper converter driving coils or inputs to the receiving set output, and switches $G$ connect the same two converter outputs to the reversing switch and course indicator. This circuit may be checked with the aid of Figure 16 in the same way Figure 17 was checked with Figure 16.

\section{(c) THREE-UNIT SINGLE-CONTROL ARRANGEMENT}

A still further simplification in the use of the reed converter in application to any of the 4-or 12-courses is shown in Figure 19. Here all switches have been combined into one unit on a common shaft. While the switch is a little more complicated, this is warranted since it is only necessary for the pilot to set one of two pointers on one dial $D$ to the color of the course he desires to fly and the direction he desires to fly on it. The proper two reed converters are selected by switch $E$, and the proper common connection between them connected to the sliding contact of the deviometer by switch $F$. The proper two converter outputs are selected by switches $I$ and $J$. $J$ also applies the $R I$ drop across resistance $R$ (fig. 11) to the volume indicator in the proper polarity. $G$ and $H$ constitute the reversing switch which operates to keep the deflection of the course-indicator needle in the same direction as the deviation of the airplane from the course. The deviometer, requiring separate adjustment, is on a separate shaft. The pilot's control panel with course indicator, volume indicator, course selector switch, control knob, and deviometer, is shown at the left in Figure 19. The course sharpness adjustment may also be put on this panel if it is so desired.

\section{APPLICATIONS OF THE REED-CONVERTER COURSE INDICATOR}

\section{AS A MAIN AIRWAYS BEACON COURSE INDICATOR}

The use of this indicator on the main long-range visual-type beacon has already been described under III, 3. Many flight tests of the reed converter on such beacons have already been made, proving the value of the reed converter as a course indicator. The reed converter has also been used on the simultaneous radiotelephone and radio range beacon. To date several reed-converter installations have been made and have proven satisfactory.

\section{USE IN HOLDING AN AIRPLANE AUTOMATICALLY ON A RADIO- BEACON COURSE}

An early application of the reed converter was realized to be that of holding an airplane automatically on a given radiobeacon course. While the details of this application have not been tried, the fact that the reed converter produces a varying current output with a polarity, depending upon the direction of deviation of the airplane 
from the course, makes it possible to use this current for control purposes, the airplane thereby being guided automatically in a horizontal plane along the radiobeacon course.

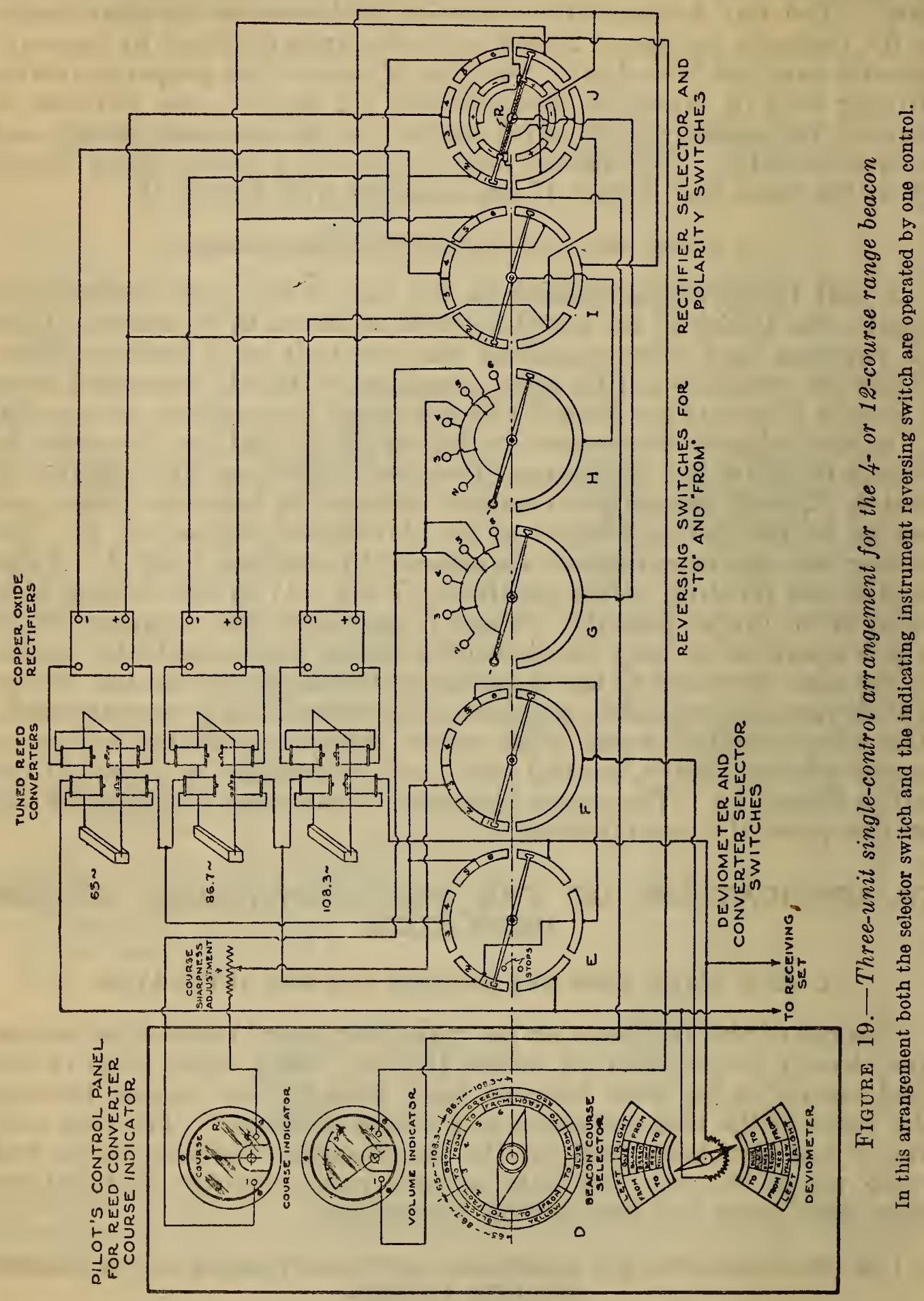

3. USE AS A COURSE INDICATOR ON THE RUNWAY LOCALIZING BEACON FOR BLIND-LANDING PURPOSES

A valuable application of the reed converter has been found in the radio system of blind-landing aids developed by the National Bureau 
B. S. Journal of Research, RP336

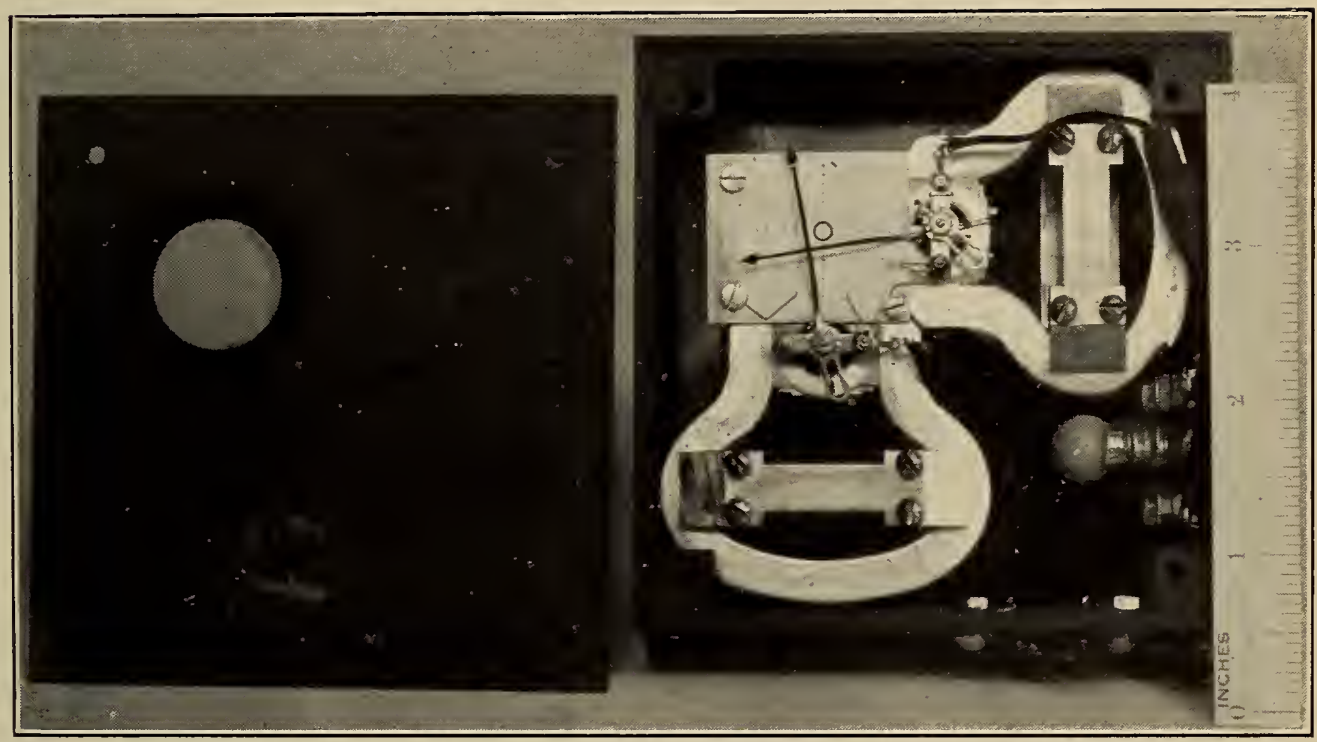

FIGURE 20.-Tuned-reed converter course indicating instrument combined with the fog landing beam indicaling instrument

The point of intersection of the pointers indicates the position of the airplane with respect to both the runway course and high-frequency landing beam path. The intersection shown indicates that the airplane is too low and off to the left. 
of Standards. ${ }^{6}$ Here the reed converter is used as a runway-localizer course indicator giving indication that the airplane is over the runway (along which the runway beacon course is oriented). Since vertical guidance is obtained by flying in on the underside of a high-frequency radiobeam, using as the indicator a 0-500 microammeter mounted horizontally, it has been found possible to combine the reed-converter runway course-indicating instrument and the fog-landing beamindicating instrument into one unit, as shown in Figure 20. Here the vertical needle is the 100-0-100 microammeter reed-converter runway-course indicator giving horizontal guidance, and the horizontal needle the high-frequency landing-beam course indicator giving vertical guidance. With the landing airplane on both courses, the two needles intersect over the circle. The needle intersection in Figure 20 shows that the airplane is below the proper glide path of the high-frequency landing beam, as the horizontal needle is below the circle, and off to the left of the runway course, as the vertical needle is

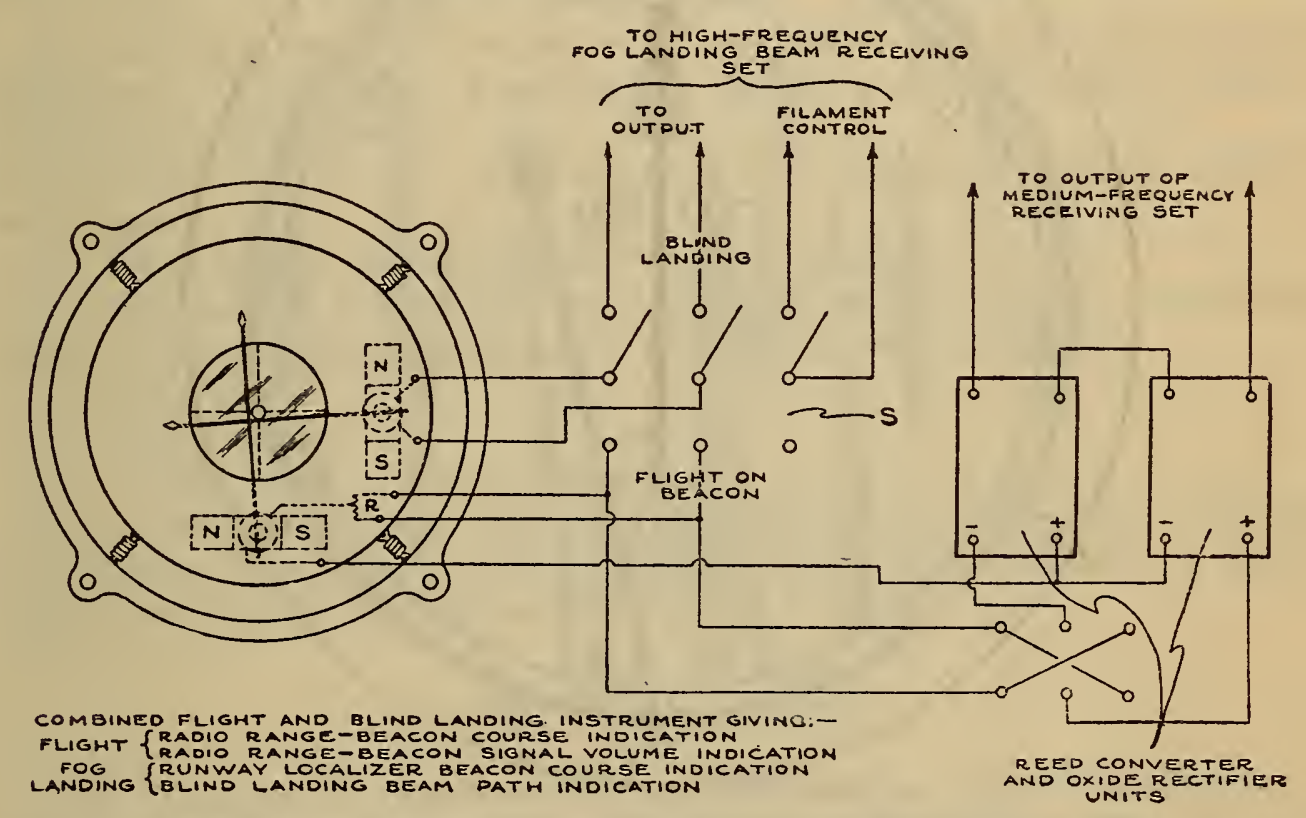

FIGURE 21.-Combined flying and landing instrument as shown in Figure 20, and connected to give: (1) main beacon-course indications; (2) signal-volume indications; (3) runway-course indications; (4) landing beam-path indications

to the left of the circle. This type of combined instrument has been found by numerous flights to be much easier to use than two separate instruments. The instrument may be made much smaller than that shown in Figure 20 and put in a round case by turning the permanent magnets (with the screws holding the pole pieces acting as a pivot) until they extend to the rear, perpendicular to the face of the instrument.

An advantage of the use of this combined instrument is that the 0-500 microammeter which is used to indicate the landing-beam path may perform a dual function, as shown in Figure 21. By means of a double-pole double-throw switch this instrument may be connected either to the output of the high-frequency fog landing beam receiver

H. Diamond and F. W. Dunmore, A Radio Beacon and Receiving System for Blind Landing of Aircraft, B. S. Jour. Research, 5 (RP238); October, 1930. Proc. 1. R. E., 19, p 585; A pril, 1931. 
and used as the landing-beam course indicator when landing in fog, or it may be connected across resistance $R$ (see also fig. 11) in the output of the oxide rectifiers, and thus may serve as the signal-volume indicator. Since the signal-volume indicator is not necessary when landing, the combined instrument is thus made to take the place of three instruments. Thus when flying on the main radio range beacon the vertical pointer gives course indication and the horizontal needle signal-volume indication. When landing in fog, the same two pointers are used, the vertical one now giving runway-course indication, since the receiving set is tuned to the runway-localizer beacon, and the horizontal pointer correct landing-beam path indications. By making

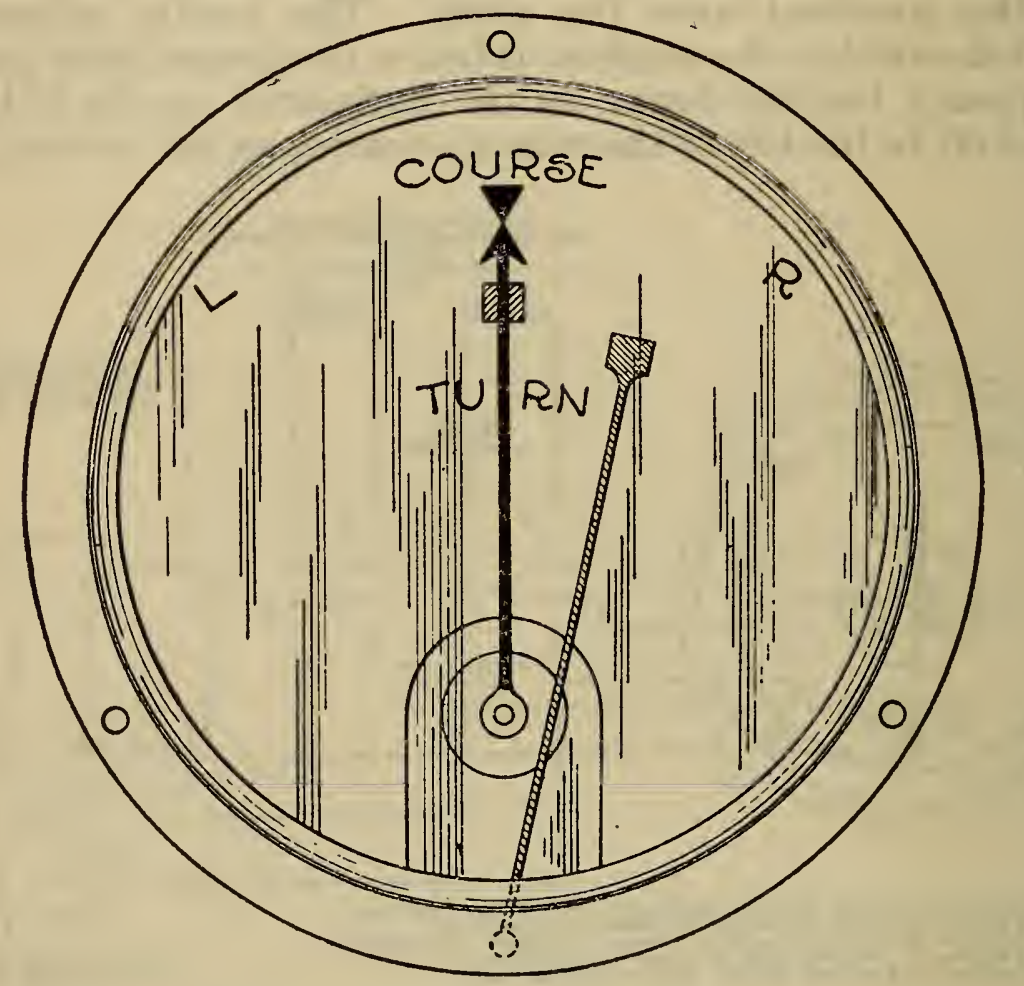

FIGURE 22.-The tuned-reed-converter course-indicating instrument combined with the turn indicator, giving both indications on one dial.

the switch of the 3-pole double-throw type as shown at $S$ (fig. 21), it may be made to turn on the landing-beam receiving set at the same time the instrument is connected to this set.

\section{COMBINATION WITH TURN INDICATOR}

Another combination of aircraft instruments made possible with the reed-converter type of indicator is that of the turn indicator and the reed-converter course-indicating instrument. Such a combination is shown in Figure 22, where the turn indicator is mounted in the rear of the zero-center beacon course indicator with a pointer on an extended shaft, traveling over the same instrument face as the pointer of the course indicator. The pointers are quite different in form to avoid confusion, and travel over different scales but on the same face. This combination greatly facilitates the use of the two instruments and saves panel space. 
V. COMPARISON OF REED CONVERTER WITH REED INDICATOR

\section{ADVANTAGES OF REED CONVERTER}

(a) Gives sharper course indications.

(b) More easily adapted in combination with other aircraft and radio instruments.

(c) Greater damping of reeds allows greater variation in the modulation frequencies at the beacon.

(d) More easily adapted to the 12-course radio range beacon.

(e) Pointer type of course indications easier to see.

(f) Adapted to holding an airplane automatically on the course.

(g) Easier to tune the reed to the required frequency.

\section{DISADVANTAGES OF REED CONVERTER}

(a) Has six elements in place of one, as is the case with the reed indicator. These are: 2 connector units, 2 oxide rectifier units, 2 indicating instruments.

(b) Requires the use of a delicate and sensitive course-indicating instrument.

(c) Requires an added signal volume indicator.

(d) Motion of course-indicator pointer under extreme interference more noticeable than movement of reeds in reed indicator.

(e) Heavier.

(f) More costly.

(g) Calibration not as permanent.

From the foregoing it is questionable which type of course indicator is superior, but it would seem that the reed converter has a definite field of usefulness as well as the reed indicator.

\section{CONCLUSION}

The tuned-reed converter as a radiobeacon course indicator described herein is made applicable to any course of a 4 or 12 course beacon by means of suitable selector switches, deviometer, volume indicator, and course sharpness adjustment. The converter consists of a common polarized tuned reed vibrating between two sets of electromagnets, one set being for driving the reed and the other set the pick-up or generating coils. The selector switch picks out the proper two reed-converter units for a given radio range beacon course and connects their outputs in the proper polarity to a zero-center course indicating instrument. A volume indicator is provided to indicate the presence of the beacon signal and the proper functioning of the receiving circuits. A color and wording system on the dial of the selector switch has been worked out so that when the pilot sets a pointer to the color of the course he is to fiy and the direction he is to fly on it, the course deviations of the course indicator will be correct.

The zero-center course indicator is readily adapted in combination with other indicating instruments, especially the fog-landing indicator and the turn indicator. The combination with the fog-landing indicator makes a single instrument which serves as a main beacon course 
indicator, signal volume indicator, runway course indicator, and landing beam path indicator.

The author is indebted to $H$. Diamond for helpful suggestions in connection with the reed-converter circuit arrangements, and to G. L Davies for suggestions relative to the design of the reed in the converter unit.

Washington, April 18, 1931. 